\title{
Probability Forecasting in Sweden: Some Results of Experimental and Operational Programs at the Swedish Meteorological and Hydrological 耳nstitente
}

\author{
KARL-IVAR IVARSSON, RUNE JOELSSON AND ERIK LILJAS \\ Swedish Meteorological and Hydrological Institute, Norrköping, Sweden
}

ALLAN H. MURPHY

Department of Atmospheric Sciences, Oregon State University, Convallis, OR 97331

(Manuscript received 21 March 1986, in final form 2 October 1986)

\begin{abstract}
This paper describes new operational and experimental forecasting programs at the Swedish Meteorological and Hydrological Institute (SMHI) designed to provide users with more detailed and more useful weather forecasts. User groups currently served by these programs include construction contractors, farmers, electric power companies, street and highway departments, and ski resorts. The programs represent a major component of a SMHI-wide effort to develop products to meet the needs of the public and private sectors in Sweden for meteorological and hydrological information.

An important feature of these programs is that many of the forecasts are expressed in probabilistic terms, and some results of the probability forecasting components of four programs are presented here. These subjective forecasts specify the likelihood of occurrence of various precipitation, wind speed, temperature, and cloud amount events, and they generally involve relatively short lead times and/or valid periods. The probabilistic forecasts of measurable precipitation are found to be reasonably reliable and definitely skillful. Some forecasts of larger precipitation amounts and the wind speed forecasts for shorter lead times also demonstrate positive skill, and the probabilistic temperature forecasts appear to be quite reliable. On the other hand, most of the experimental and operational probability forecasts reveal some degree of overforecasting, which tends to increase as lead time increases and as the climatological probability of the event decreases. As a result, the wind speed forecasts for longer lead times, some forecasts of precipitation amount, and the cloud amount forecasts exhibit negative skill.

Some factors that may have contributed to the deficiencies in the forecasters' performance are identified. The need to refine various components of the forecasting system is emphasized, and current efforts to implement such refinements at SMHI are outlined.
\end{abstract}

\section{Hintroduction}

The Swedish Meteorological and Hydrological Inscitute (SMHI) has recently initiated several experimental and operational programs designed to provide particular user groups-including the general publicwith more detailed and more useful weather forecasts. User groups currently served by the programs include construction contractors (buildings and roads), farmers, electric power companies, street and highway departments, and ski resorts. These forecasting programs represent a major component of a comprehensive effort at SNEIII to develop a full range of services to support the needs of the public and private sectors in Sweden for meteorological and hydrological information.

An important feature of these programs is that many of the forecasts are expressed in probabilistic terms. It is now widely recognized that quantitative assessments of the uncertainty inherent in forecasts are required to ensure that rational and optimal use can be made of such information (e.g., see Murphy, 1985). More spe- cifically, the economic value of probabilistic forecasts generally exceeds the economic value of forecasts expressed in nonprobabilistic terms (e.g., Murphy, 1977; Krzysztofowicz, 1983).

The forecasts produced in conjunction with SMHI's new experimental and operational forecasting programs are subjective forecasts. That is, the forecasts represent the output of a forecasting process in which the subjective judgments of individual forecasters play a major role (of course, these judgments are often strongly influenced by various objective inputs). Considerable evidence now exists that weather forecasters generally can quantify the uncertainty in their forecasts in a reliable and skillful manner (e.g., see Murphy, 1985). However, recent studies (e.g., Daan and Murphy, 1982; Murphy and Winkler, 1982; Murphy et al., 1985) have shown that subjective probabilistic forecasts sometimes exhibit significant biases, especially in the early stages of new forecasting programs when forecasters are relatively inexperienced in quantifying the uncertainty associated with their forecasts. Since these 
biases can adversely affect the usefulness of the forecasts, studies of forecast quality frequently assume a particularly important role in such situations. For example, it may be possible to reduce the aforementioned biases by providing the forecasters with feedback concerning their individual and/or collective performance (see Murphy and Daan, 1984).

The primary purposes of this paper are (i) to describe the new experimental and operational forecasting programs at SMHI and (ii) to present some results of the probability forecasting components of several programs. These programs are briefly described in section 2 , which also contains a table summarizing the important characteristics of the probability forecasting activities. Results of four of the probability forecasting activities are presented in section 3-the results relate to forecasts of precipitation occurrence, snowfall amount, and wind speed for construction contractors, forecasts of precipitation amount for farmers, forecasts of temperature for electric power companies, and forecasts of cloud amount for cucumber growers. Particular attention is focused on the reliability and/or skill of the subjective probabilistic forecasts. In section 4 the major features of these results are discussed and the results of the SMHI probability forecasting activities are compared with the results of experimental and/or operational probability forecasting programs in other countries. This section concludes with an outline of plans for future work in this area at SMHI.

\section{Probability forecasting at SMHI: An overview}

In this section we describe new specialized forecasting programs at SMHI that possess significant probability forecasting components. The four programs for which results are presented in section 3 are considered in some detail. A catalogue summarizing the key features of the probability forecasting components of all of the programs appears in Table 1 . The section concludes with a short discussion of the guidance information available to SMHI forecasters in the preparation of their probabilistic (and nonprobabilistic) weather forecasts.

\section{a. Specialized forecasting programs}

\section{1) BYGGVÄDERPROGNOSER PROGRAM}

A major specialized forecasting program referred to as the Byggväderprognoser ("construction weather forecasting") program was undertaken by SMHI in 1980. In this program detailed weather forecasts up to three days in advance are produced for several locations in Sweden during the winter months of November through March. These forecasts are provided to building construction firms who use the information in making decisions related to job scheduling, manpower utilization, and site protection.
In the Byggväderprognoser program, short-range forecasts are produced for temperature, precipitation occurrence and type, snowfall amount, and average and maximum wind speeds. Three basic forecasts are provided each day. At 0640 , forecasts are produced for three consecutive two-hour periods followed by a threehour period. (Note: All times in this paper are LST.) These forecasts cover the daytime hours from 0700 to 1600 . At 1445 , forecasts are produced for a 15 -h nighttime period (1600-0700) and two daytime periods (morning: 0700-1200 and afternoon: 1200-1600). Also at 1445 , a separate forecast is prepared that covers four consecutive 12 -h periods beginning at 1900 the following day.

The forecasts of precipitation occurrence and type, snowfall amount, and maximum wind speed are expressed in probabilistic terms. For precipitation occurrence, the forecasts specify the probability that the amount of precipitation will equal or exceed $0.1 \mathrm{~mm}$. In the case of precipitation type, the probabilities indicate the likelihood that the type of precipitation will be rain, snow, rain showers, or snow showers. The probabilistic forecasts of snowfall amount specify the probabilities that the amounts of snowfall in the respective periods will exceed 0,3 , or $10 \mathrm{~cm}$. For wind speed, probabilities are provided for maximum wind speeds exceeding 8 and $15 \mathrm{~m} \mathrm{~s}^{-1}$ in these periods.

\section{2) PROFARM PROGRAM}

Another major forecasting program recently initiated by SMHI is the so-called PROFARM program. In this program, weather forecasts are provided for several key agricultural areas during the months of April through October. Two types of forecasts are produced in the PROFARM program, detailed short-range forecasts for relatively small areas and more general short/mediumrange forecasts for larger areas.

The primary short-range forecast is made at 0630 each day and contains information related to overall weather conditions, precipitation amount and type, temperature, and average and maximum wind speeds in four consecutive three-hour periods, followed by four consecutive six-hour periods. In addition to the primary forecast, updated forecasts for the same elements and periods are produced at 1100 and 1500 . In 1985, these forecasts were provided for two areas, Vikbolandet and Vadstena-Skänninge-Motala, and a total of ten farmers participated in the experimental program. The farmers obtained the forecasts either via a videotex terminal in their homes (linked to the SMHI computer system) or via a recorded telephone message.

Short-range forecasts for two weather elements are expressed in probabilistic terms: (i) precipitation amount and (ii) frost (i.e., freezing temperature). In the case of precipitation amount, the forecaster assesses probabilities that the amounts of precipitation in the respective periods will exceed $0.1 \mathrm{~mm}$, or equal or ex- 


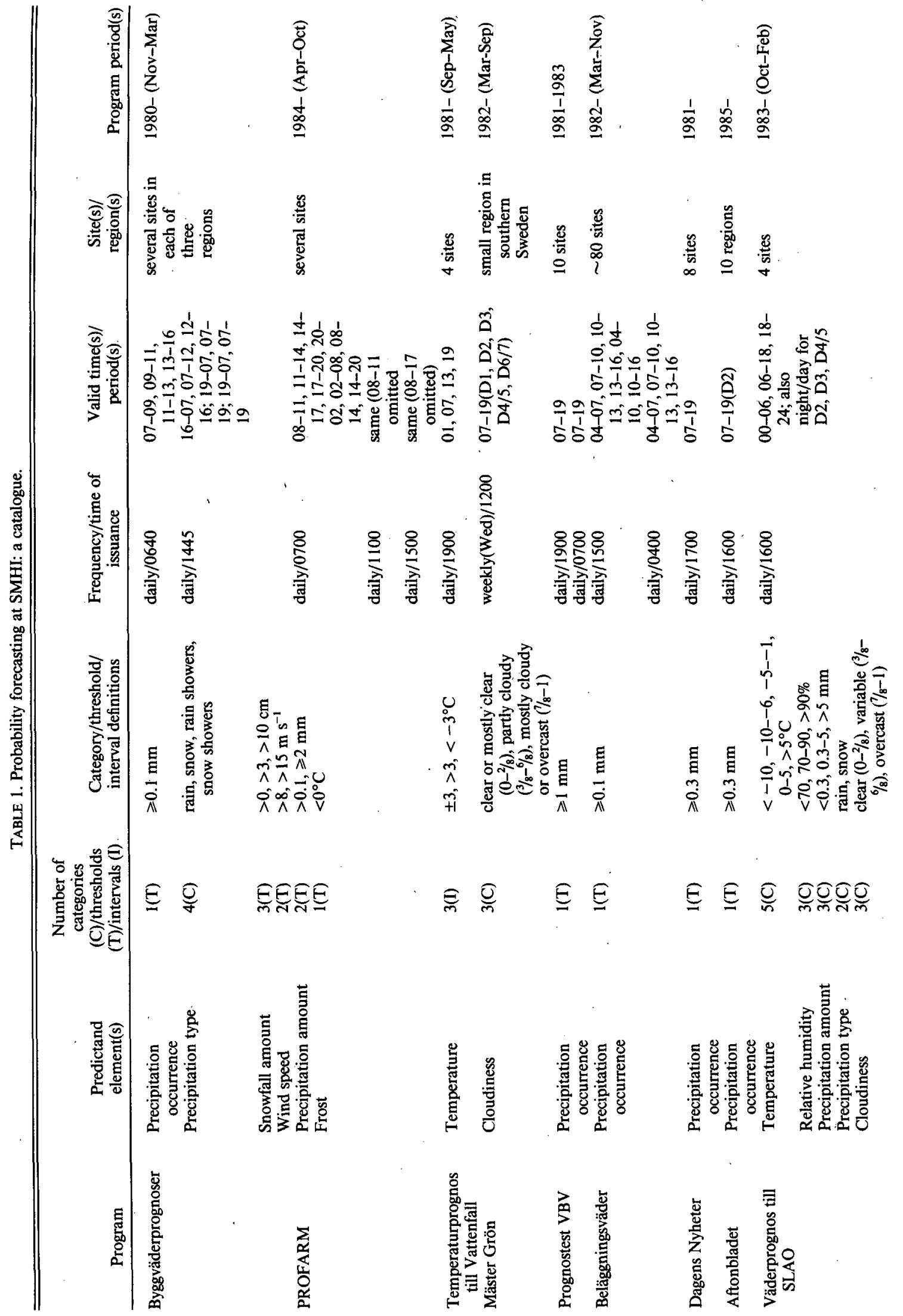




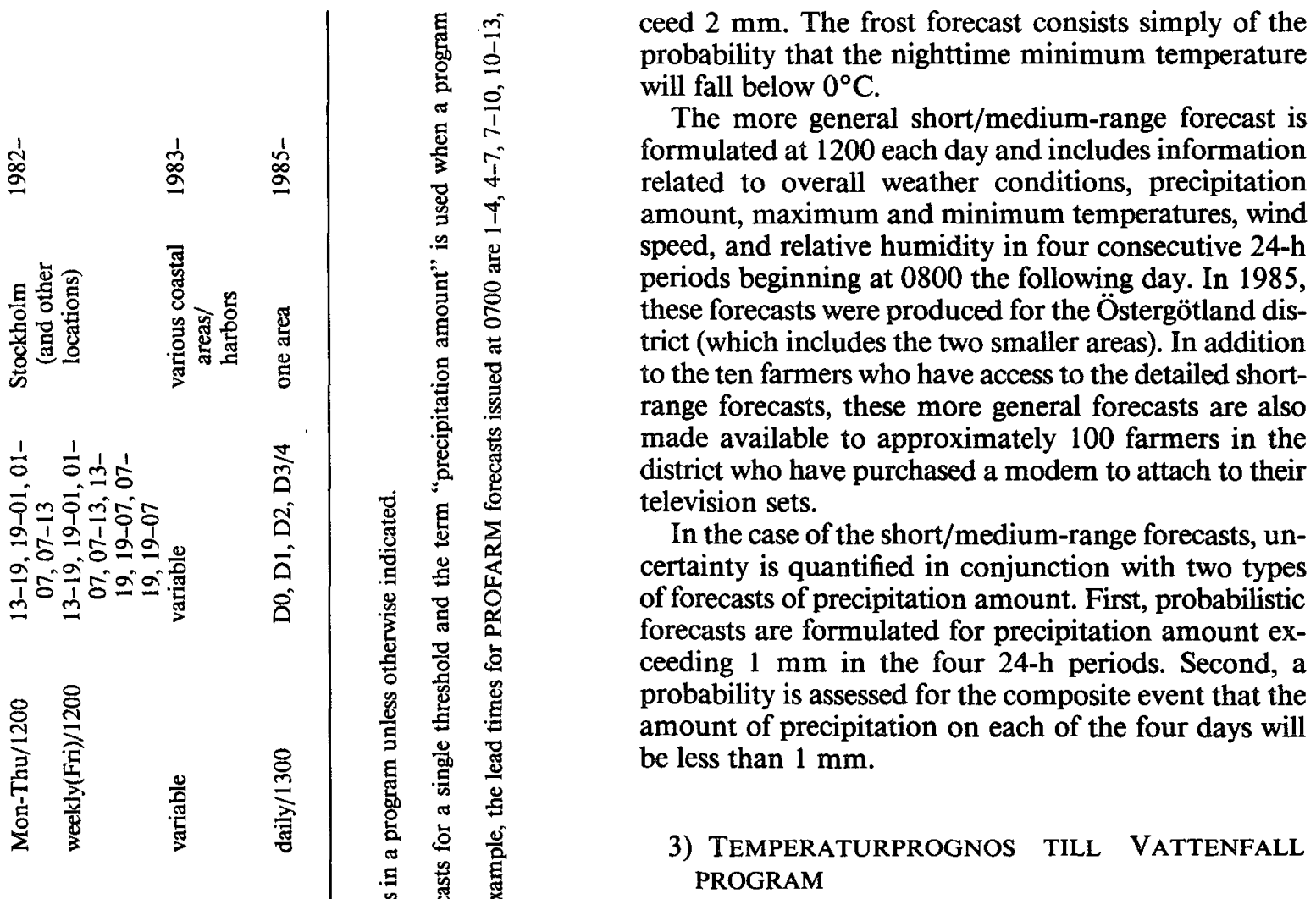

The Temperaturprognos till Vattenfall program was undertaken in 1981 and involves the formulation of temperature forecasts for four widely separated locations in Sweden. More precisely, temperature forecasts are prepared at 1900 each day for four specific times the following day-namely, $0100,0700,1300$, and 1900. These forecasts are provided to electric utility companies who use the information in estimating consumption and in making decisions regarding energy distribution.

Two types of temperature forecasts are produced, point estimates and credible intervals. A point estimate consists of an unqualifed forecast of a specific temperature value, and it represents the forecaster's best estimate of the temperature to be observed at the time in question. A credible interval, on the other hand, is an interval of temperature values accompanied by a probability that describes the forecaster's "degree of belief" that the observed temperature will fall in the interval. In this program, the forecasters assess probabilities for three intervals: a central interval $\pm 3^{\circ} \mathrm{C}$ on each side of the point estimate, an open-ended interval above the central interval, and an open-ended interval below the central interval (the central interval includes its endpoints). In the terminology of credible interval temperature forecasting, the central interval is referred to as a fixed-width, variable-probability interval (see Murphy and Winkler, 1974; Winkler and Murphy, 1979). 


\section{4) MÄSTER GRON PROGRAM}

In 1982, SMHI initiated the Mäster Grön ("Mr. Green") program in which forrecasts of cloud amount are formulated for a small region (western Skåne) in southern Sweden during the months of March through September. The forecasts are made each week on Wednesday at 1200 , and they are valid for the daytime hours (approximately 0700-1900) on Thursday, Friday, Saturday, Sunday/Monday, and Tuesday/ Wednesday. These forecasts are provided to cucumber growers who use the information in estimating shortterm domestic production as well as in making decisions related to possible imports of this product. The cloud amount forecasts are expressed in probabilistic terms. Specifically, the forecasts indicate the probability that the average cloud amounts in the respective 12$h$ (one-day) or 24-h (two-day) periods will fall in each of three categories.

\section{5) OTHER PROGRAMS}

The key features of the probability forecasting components of eight other specialized forecasting programs are also described in Table 1. These programs include the Prognostest VBV program in which precipitation probability forecasts were produced on an experimental basis (this program was terminated in 1983 because of the work load associated with other programs); the Beläggningsväder program which produces precipitation probability forecasts for construction contractors; the Dagens Nyheter and Aftonbladet programs which provide the same type of forecasts for the general public (via newspapers); the Väderprognos till SLAO program in which probabilistic forecasts of temperature, relative humidity, precipitation amount and type, and cloudiness are routinely distributed to operators of ski lifts; the winter roads program in which probabilistic forecasts of precipitation occurrence and snowfall amount are disseminated to selected street and highway maintenance authorities; the marine program under which probabilistic forecasts of precipitation occurrence, wind speed, and visibility are distributed to marine interests in coastal areas and harbors; and the Övre Indalsäven program in which probabilistic precipitation amount forecasts are provided to reservoir managers in a catchment basin in western Sweden.

\section{b. Guidance information available to forecasters}

Several types of guidance information are available to SMHI forecasters when they formulate their probabilistic (and nonprobabilistic) weather forecasts. First, the forecasters have access to a variety of direct output-analyses and forecasts-from the numerical model at the European Center for Medium-Range Weather Forecasts (ECMWF). Among the more important products from this source are the planetaryscale and synoptic-scale circulations at selected levels, fields of cloud amount and relative humidity, and surface or near-surface quantities such as 10-meter winds, 2-meter temperatures, and precipitation amounts. A limited number of products derived from statistical interpretation of ECMWF model output are also available. These objective products, which are based on both perfect prognosis and model output statistics approaches, include precipitation probability forecasts for southern Sweden and forecasts of convective storm indices related to thunderstorm occurrence.

In addition to the direct use of this objective guidance information in the subjective forecasting process, it also plays an important role in the preparation, by the forecasters, of prognostic charts containing frontal zones, areas of precipitation and other weather events, and temperature and wind data. These charts are particularly useful in the formulation of probabilistic forecasts involving small geographical areas and/or short lead times. In addition, relevant climatological data, when available, are carefully considered in the process of preparing the specialized forecasts.

In the case of the short-range forecasts, observations from synoptic and automatic stations-as well as radar and satellite data-also represent important sources of guidance information. For forecasts with lead times exceeding 12-18 hours, objective guidance produced by, or derived from, numerical models plays an increasingly important role.

\section{Some results}

In this section we present some results from the four programs described in detail in section 2a. First, however, the procedures used to verify the forecasts are briefly discussed.

\section{a. Methods of verification}

Since the forecasts of interest are probabilistic forecasts, it is necessary to employ probabilistic measures of performance to evaluate the forecasts. In particular, we want to assess the extent to which the forecasts possess certain desirable properties, such as accuracy, reliability, resolution, and skill. The basic measure of accuracy considered here is the Brier score (Brier, 1950), which represents the mean squared error of probabilistic forecasts. In computing this score, the observations are treated as binary variables, with event occurrence (nonoccurrence) represented by a "one", ("zero"). Brier scores range from zero (perfect forecasts) to two (completely imperfect forecasts).

Skill is generally defined as the accuracy of the forecasts relative to the accuracy of forecasts produced by some standard of reference such as climatology or persistence. The standard of reference employed here is sample climatology (i.e., climatological probabilities of the events derived from the observations associated 
with the sample of forecasts). We can define a skill score (SS) as follows:

$$
\mathrm{SS}=[(\mathrm{BSSC}-\mathrm{BS}) / \mathrm{BSSC}] \times 100,
$$

where BS is the Brier score of the forecasts and BSSC is the Brier score of forecasts based solely on sample climatological probabilities. Thus, SS represents the percentage improvement in the forecasts over sample climatology. It equals 100 for perfect forecasts and zero for forecasts for which BS equals BSSC (no skill). Skill is negative when the climatological probabilities are more accurate than the forecast probabilities.

The concepts of reliability and resolution can be developed within a framework in which the overall data sample is divided into subsamples, each of which consists of all of the forecasts and observations associated with a particular probability value (or range of probability values). In this framework, reliability relates to the correspondence between forecast probabilities and observed relative frequencies in the respective subsamples, and resolution relates to the differences between subsample relative frequencies and overall sample relative frequency. According to terminology introduced by Sanders (1963), reliability is concerned with the forecaster's (or forecast system's) ability to label the subsamples properly, whereas resolution is concerned with the forecaster's ability to sort the sample into subsamples whose observed relative frequencies are maximally different (this latter attribute relates more directly to meteorological knowledge and expertise).

To obtain quantitative measures of reliability and resolution, we employ a partition of the Brier score formulated by Murphy (1973). According to this partition,

$$
\mathrm{BS}=\mathrm{BSSC}+\mathrm{REL}-\mathrm{RES},
$$

where REL is a quadratic measure of reliability and RES is a quadratic measure of resolution. Both REL and RES are nonnegative and, since BS has a negative orientation (i.e., smaller scores are better), we can refer to REL as the (lack of) reliability "penalty" and to RES as the resolution "reward." Substitution of the expression for BS in (2) into (1) yields a useful form of SS; namely,

$$
\mathrm{SS}=[(\mathrm{RES}-\mathrm{REL}) / \mathrm{BSSC}] \times 100 .
$$

Thus, probabilistic forecasts have positive skill when the resolution reward exceeds the reliability penalty.

The reliability of a sample of probabilistic forecasts can be assessed visually by means of a reliability diagram (e.g., Murphy and Winkler, 1977; Murphy, 1985). In such a diagram, observed relative frequency is plotted against forecast probability for specific probability values (in the case of the results presented here, the permissible probability values are $0.00,0.05,0.10,0.20$, . . . , 1.00). The diagonal $45^{\circ}$ line in the diagram represents perfect reliability, in the sense that observed relative frequency exactly equals forecast probability.
Comparison of the empirical "curve" (consisting of at most 11 line segments) with this diagonal line provides an indication of the reliability of the individual subsamples and the overall sample of forecasts. It is also important to consider the frequency with which the twelve probability values are used. This frequency-ofuse (or predictive) distribution can be plotted and displayed in combination with the reliability diagram.

These and other methods of evaluating probabilistic weather forecasts are described in greater detail by Murphy and Daan (1985). For examples of the application of this methodology, refer to Daan and Murphy (1982), Murphy and Daan (1984), Murphy et al. (1985), Murphy and Winkler (1982), and Winkler and Murphy (1979).

\section{b. Byggväderprognoser program}

This program involves the preparation of short-range forecasts of several weather elements and events for construction companies whose operations involve various regions and sites in Sweden. Here, we examine the quality of the probabilistic forecasts of precipitation occurrence $(\geqslant 0.1 \mathrm{~mm})$, snowfall amount $(>0 \mathrm{~cm},>3$ $\mathrm{cm}$ ), and wind speed ( $>8 \mathrm{~m} \mathrm{~s}^{-1}$ ) for Norrköping (see Fig. 1), issued during the period 25 October 1984 to 20 March 1985. For each element/event combination, results are presented separately for four different lead times (or "days"), each of which consists of two or more valid periods [namely, Day 0 (D0): four periods, Day 1 (D1): three periods, Day 2 (D2): two periods, and Day 3 (D3): two periods; see Table 1]. In evaluating these results, it is important to recognize that the average valid period of the forecasts is $2,8,12$, and 12 hours for D0, D1, D2, and D3, respectively. Observations of the relevant weather elements and events taken at the Swedish Air Force Base near Norrköping were the primary source of data used to verify the forecasts. Since snowfall amount is generally measured only on a 12-h or 24-h basis, some difficulties were encountered in distributing snowfall amounts among various valid periods. These difficulties may have affected the evaluation of the snowfall amount forecasts.

\section{1) Precipitation occurrence}

Reliability diagrams for the precipitation occurrence forecasts are depicted in Fig. 2, with separate curves included for each day. Overall quantitative measures of reliability, resolution, and skill associated with these curves are presented in Table 2 . The empirical curve for D0 reveals overforecasting for most probability values, but these forecasts still attain a positive overall skill score of $16.9 \%$. For the D1 forecasts, underforecasting occurs for probability values less than or equal to 0.30 and overforecasting occurs for higher probability values. Although the empirical curves for D2 and D3 do not exhibit any strong overall biases or trends, 


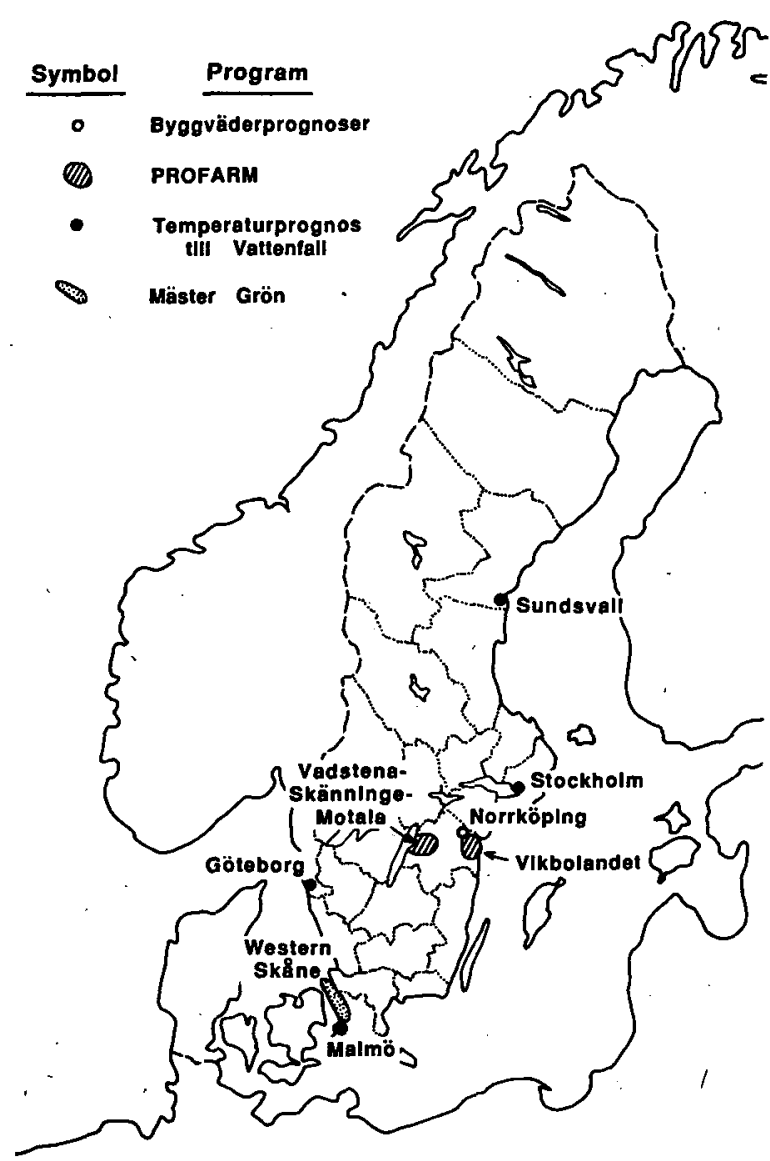

FIG. 1. Map of Sweden showing locations of stations or regions for which probabilistic forecasts were prepared in conjunction with four specialized forecasting programs (see text for additional details).

substantial underforecasting occurs for both lead times for most low probability values. Since these values are used more frequently than higher values (see inset in Fig. 2), the corresponding REL values are quite large and the corresponding skill scores are relatively low. (Note: The forecasters evidently have an aversion to using the probability value 0.05 , perhaps because it is not a member of the set of 11 uniformly spaced values.) Thus, a tendency exists for overforecasting to decrease (or underforecasting to increase) as lead time increases-of course, as indicated above, the average length of the valid period also increases as lead time increases. In addition, it should be noted that the frequency of use of higher probability values decreases as lead time increases. Finally, skill decreases monotonically from D0 to D3.

\section{2) SNOWfall Amount}

For forecasts of snowfall amount greater than $0 \mathrm{~cm}$, reliability diagrams are included in Fig. 3 and overall measures of the basic attributes are presented in Table 3a. These results are similar in many respects to the results for the precipitation occurrence forecasts. For example, a tendency exists for overforecasting to occur at the shortest lead times (i.e., D0) and for underforecasting to occur at longer lead times (i.e., D2 and D3). However, the D2 and D3 snowfall amount forecasts for this threshold are considerably more reliable than the D2 and D3 precipitation occurrence forecasts (cf. Tables 2 and $3 \mathrm{a}$ ). As a result, the skill of the former exceeds that of the latter and is at least modestly positive at all lead times. The frequency of use of higher probability values also decreases as lead time increases for these snowfall amount forecasts (see inset in Fig. 3) and skill decreases monotonically from D0 to D3.

Analogous results for the forecasts of snowfall amount greater than $3 \mathrm{~cm}$ are presented in Fig. 4 and Table $3 \mathrm{~b}$. In this case', it was possible to verify only the forecasts for valid periods in D2 and D3. The empirical curves in Fig. 4 reveal overforecasting for most probability values, but the amount of overforecasting is relatively modest in an overall sense (cf. average forecast probabilities and observed relative frequencies in Table $3 b)$. It is somewhat surprising to note that the skill of the D3 forecasts exceeds the skill of the D2 forecasts $(5.5 \%$ versus $-0.8 \%)$. However, this difference easily could be reversed by small changes in the frequencyof-use distributions or observed relative frequencies. In this regard, it should be noted that probabilities as high as 0.50 were used on less than ten occasions for both lead times for these forecasts. Finally, as expected, the snowfall amount forecasts for the larger threshold are less skillful than the snowfall amount forecasts for the smaller threshold (cf. Tables $3 a$ and $3 b$ ).

\section{3) WIND SPEED}

Reliability diagrams for the maximum wind speed forecasts for the $8 \mathrm{~m} \mathrm{~s}^{-1}$ threshold are depicted in Fig. 5 and the corresponding overall measures of reliability, resolution, and skill are presented in Table 4 . A general tendency can be seen for underforecasting for low probability values and overforecasting for high probability values, with the strength of this tendency increasing as lead time (and length of average valid period) increases. Specifically, the DO forecasts are quite reliable with only a modest tendency toward overforecasting for probability values greater than 0.50 . For the D1 forecasts, moderate underforecasting occurs for low probability values. In the cases of the D2 and D3 forecasts, however, marked underforecasting occurs for low probability values and substantial overforecasting occurs for high probability values, with the result that the slopes of the empirical curves are only slightly positive. The REL values in Table 4 indicate quantitatively the rate of deterioration in the reliability of these forecasts as a function of lead time. When this deterioration in reliability is combined with the not unexpected decrease in resolution as lead time increases, it leads to marked changes in skill from D0 to D3. In this regard, 

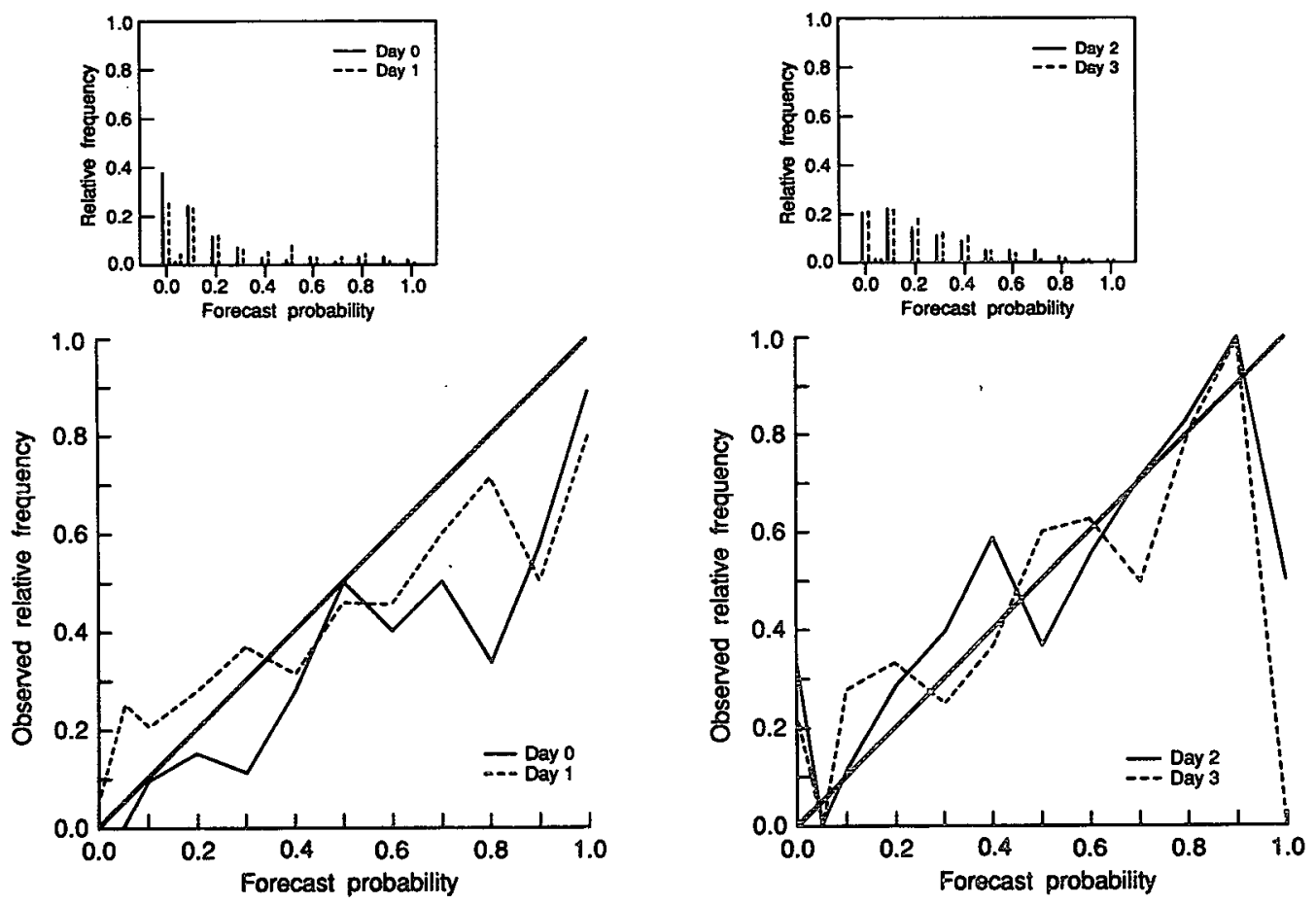

FIG. 2. Reliability diagrams for precipitation occurrence forecasts formulated in Byggväderprognoser program for (a) Days 0 and 1 and (b) Days 2 and 3. Insets contain frequency-of-use distributions for various probability values.

the skill score for D0 is strongly positive $(31.1 \%)$, whereas the skill scores for D2 and D3 are negative $(-13.6 \%$ and $-27.9 \%$, respectively).

\section{c. PROFARM program}

As noted in section $2 a$, this program includes the formulation of probabilistic forecasts for precipitation amounts exceeding $0.1 \mathrm{~mm}$ and equaling or exceeding $2 \mathrm{~mm}$ in four 3-h and four 6-h periods (see Table 1). In this section we investigate the quality of forecasts of these precipitation events formulated at 0700 each day during the period 16 April-7 October 1985 for Vikbolandet and Vadstena-Skänninge-Motala (see Fig. 1 for the location of these areas). Observations of precipitation amounts in the respective periods, ob- tained from recording raingages in these two areas, provided the data required to verify the forecasts.

A reliability diagram for the 3-h period forecasts is presented in Fig. 6. Separate curves are included for the 0.1 and $2 \mathrm{~mm}$ thresholds (or events). First, it should be noted that the two events occurred on 18.8 and $5.3 \%$, respectively, of the 3-h periods for which these forecasts were prepared. The empirical curve corresponding to the smaller threshold $(0.1 \mathrm{~mm})$ reveals that these forecasts are quite reliable for probability values less than or equal to 0.30 but that overforecasting occurs for higher probability values. For the forecasts associated with the larger threshold $(2 \mathrm{~mm})$, considerable overforecasting occurs for all probability values greater than 0.10 . Note that, whereas the full range of probability values is used in the case of the smaller-threshold

TABLE 2. Overall reliability, resolution, and skill of precipitation probability forecasts formulated in Byggväderprognoser program for Norrköping for various lead times.

\begin{tabular}{cccccccrr}
\hline \hline $\begin{array}{c}\text { Lead } \\
\text { time } \\
\text { (days) }\end{array}$ & $\begin{array}{c}\text { Average } \\
\text { valid } \\
\text { period } \\
\text { (hours) }\end{array}$ & $\begin{array}{c}\text { Number } \\
\text { of } \\
\text { forecasts }\end{array}$ & $\begin{array}{c}\text { Average } \\
\text { forecast } \\
\text { probability }\end{array}$ & $\begin{array}{c}\text { Observed } \\
\text { relative } \\
\text { frequency }\end{array}$ & $\begin{array}{c}\text { Brier score } \\
\text { for sample } \\
\text { climatology } \\
\text { BSSC }\end{array}$ & $\begin{array}{c}\text { Reliability } \\
\text { REL }\end{array}$ & $\begin{array}{c}\text { Resolution } \\
\text { RES }\end{array}$ & $\begin{array}{c}\text { Skill } \\
\text { score } \\
\text { SS (\%) }\end{array}$ \\
\hline 0 & 2 & 396 & 0.20 & 0.139 & 0.120 & 0.016 & 0.036 \\
1 & 8 & 297 & 0.25 & 0.276 & 0.200 & 0.012 & 0.036 \\
2 & 12 & 197 & 0.26 & 0.355 & 0.229 & 0.030 & 0.040 & 16.9 \\
3 & 12 & 198 & 0.24 & 0.333 & 0.222 & 0.027 & 0.026 \\
\hline
\end{tabular}



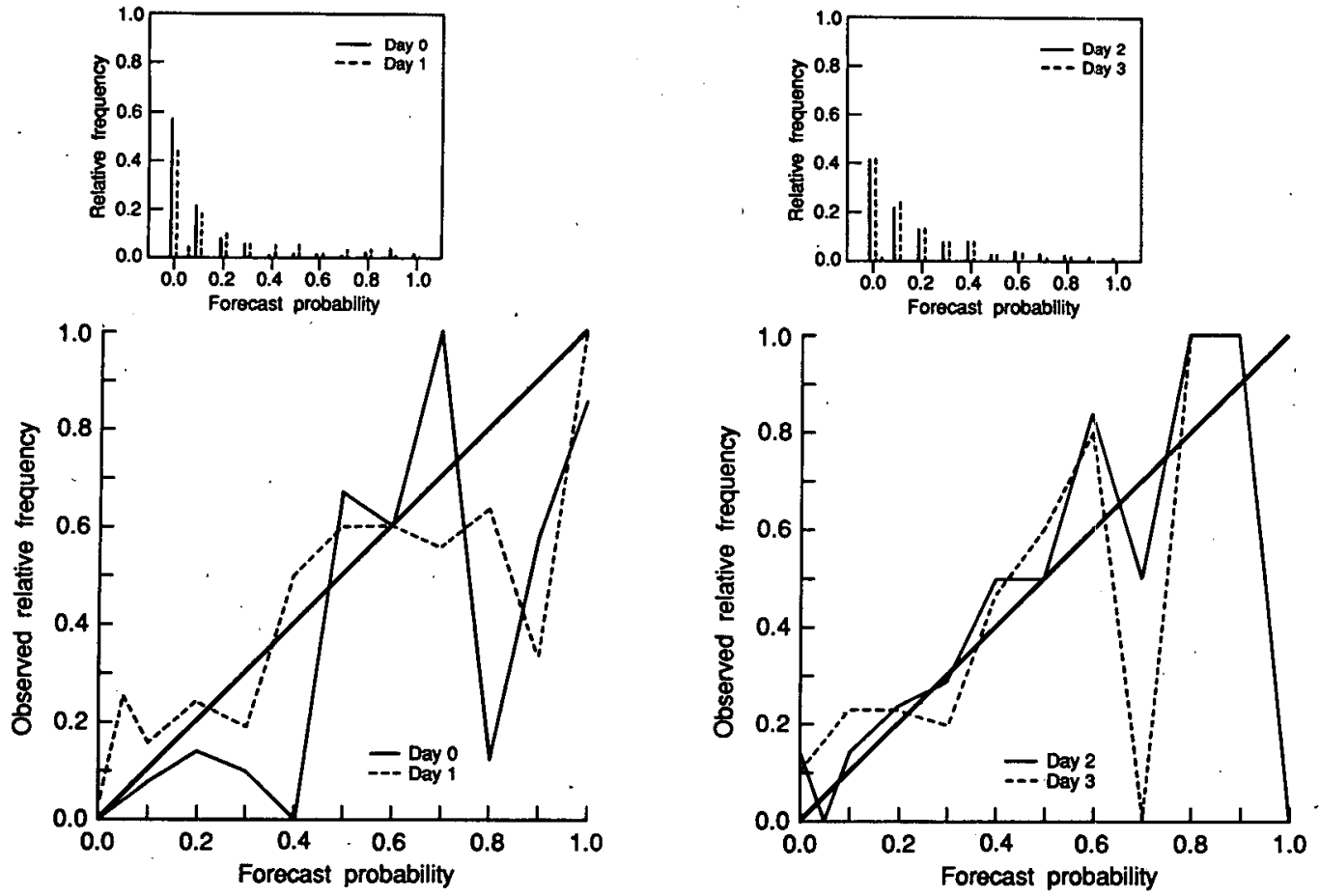

FIG. 3. As in Fig. 2 but for snowfall amount forecasts for $0 \mathrm{~cm}$ threshold.

forecasts, probability values employed in the largerthreshold case never exceed 0.70 .

Quantitative estimates of the reliability, resolution, and skill of the 3-h probabilistic forecasts for these two events are included in Table 5. For the smaller-threshold forecasts, skill is positive for most probability values, and the overall skill score is $21.3 \%$. In the case of the $2 \mathrm{~mm}$ forecasts, a relatively large REL value (indicative of overforecasting in this case) together with a very modest RES value lead to negative skill scores for several probability values and to an overall skill score of $-13.3 \%$ for this fairly rare event.
Measures of overall reliability, resolution, and skill for the 3-h forecasts as a function of lead time are presented in Table 6 . For the $0.1 \mathrm{~mm}$ threshold forecasts, reliability remains relatively constant and resolution decreases as lead time increases. As a result, forecasts at longer lead times exhibit lower skill scores. Nevertheless, the skill scores are positive for all four lead times for these forecasts. In the case of the $2 \mathrm{~mm}$ threshold forecasts, both reliability and resolution remain relatively constant as lead time increases, with the magnitude of the former exceeding that of the latter for each lead time. Thus, skill is negative at all lead

TABLE 3. Overall reliability, resolution, and skill of snowfall amount forecasts formulated by Byggväderprognoser program for Norrköping for various lead times.

\begin{tabular}{|c|c|c|c|c|c|c|c|c|}
\hline $\begin{array}{l}\text { Lead } \\
\text { time } \\
\text { (days) }\end{array}$ & $\begin{array}{l}\text { Average } \\
\text { valid } \\
\text { period } \\
\text { (hours) }\end{array}$ & $\begin{array}{l}\text { Number } \\
\text { of } \\
\text { forecasts }\end{array}$ & $\begin{array}{c}\text { Average } \\
\text { forecast } \\
\text { probability }\end{array}$ & $\begin{array}{l}\text { Observed } \\
\text { relative } \\
\text { frequency }\end{array}$ & $\begin{array}{c}\text { Brier score } \\
\text { for sample } \\
\text { climatology } \\
\text { BSSC }\end{array}$ & $\begin{array}{c}\text { Reliability } \\
\text { REL }\end{array}$ & $\begin{array}{l}\text { Resolution } \\
\text { RES }\end{array}$ & $\begin{array}{c}\text { Skill } \\
\text { score } \\
\text { SS (\%) }\end{array}$ \\
\hline \multicolumn{9}{|c|}{ (a) Snowfall amount $>0 \mathrm{~cm}$} \\
\hline 0 & 2 & 396 & 0.14 & 0.091 & 0.083 & 0.018 & 0.036 & 22.3 \\
\hline 1 & 8 & 297 & 0.17 & 0.195 & 0.157 & 0.009 & 0.041 & 20.5 \\
\hline 2 & 12 & 197 & 0.17 & 0.244 & 0.184 & 0.017 & 0.040 & 12.5 \\
\hline 3 & 12 & 198 & 0.14 & 0.227 & 0.176 & 0.015 & 0.028 & 7.7 \\
\hline \multicolumn{9}{|c|}{ (b) Snowfall amount $>3 \mathrm{~cm}$} \\
\hline 2 & 12 & 199 & 0.08 & 0.060 & 0.057 & 0.011 & 0.011 & -0.8 \\
\hline 3 & 12 & 198 & 0.07 & 0.066 & 0.061 & 0.010 & 0.014 & 5.5 \\
\hline
\end{tabular}




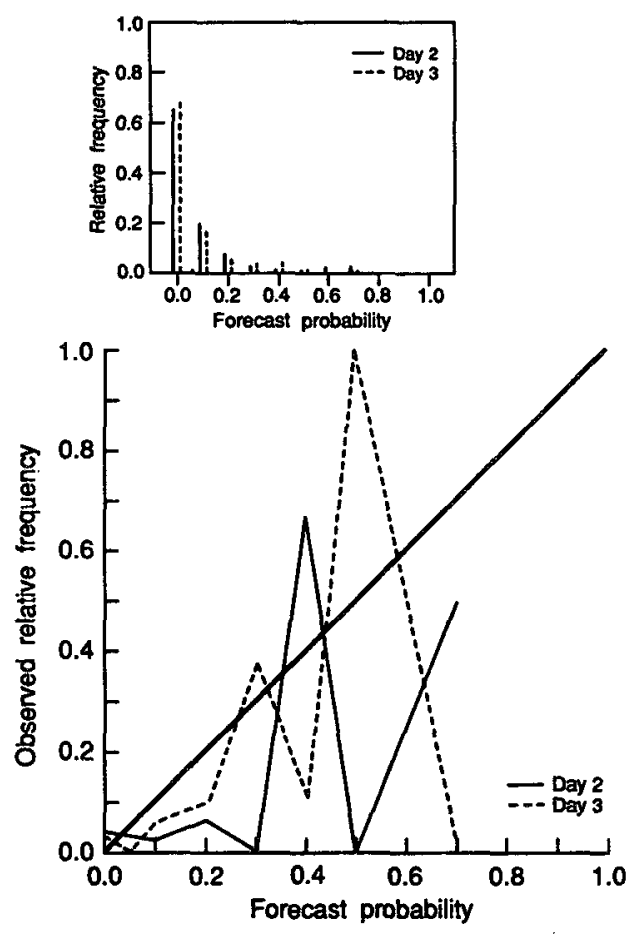

FIG. 4. As in Fig. 3 but for $3 \mathrm{~cm}$ threshold.

times. It is of interest to note that, for the forecasts involving this larger precipitation threshold, skill increases as observed relative frequency increases.

The reliability diagram for the 6-h period forecasts is depicted in Fig. 7. For these periods, the 0.1 and 2 mm events occurred on 23.7 and $7.8 \%$, respectively, of the forecasting occasions. The empirical curve for the $0.1 \mathrm{~mm}$ forecasts corresponds quite closely to the perfect reliability line, although a modest but systematic tendency toward underforecasting can be seen for probability values less than 0.30 and some overforecasting is evident for higher probability values. For the $2 \mathrm{~mm}$ forecasts, the empirical curve corresponds very closely to the $45^{\circ}$ line for probability values less than or equal to 0.20 , but exhibits a somewhat erratic behavior for higher probability values. It should be noted that the range of probability values used in the $2 \mathrm{~mm}$ forecasts is quite limited, with only four forecasts associated with a probability value as high as 0.60 .

Values of the reliability, resolution, and skill measures for the 6-h forecasts for each event are included in Table 7. Overall skill is positive for both events, with the skill score for the $0.1 \mathrm{~mm}$ threshold forecasts (16.7\%) exceeding the skill score for the $2 \mathrm{~mm}$ threshold forecasts $(9.9 \%)$. In comparing the performance of the forecasts for the 3-h and 6-h periods, it is of interest to note that the former are more skillful for the smaller threshold but that the latter are more skillful for the larger threshold (recall that the lead times of the 6-h forecasts are all longer than the lead times of the 3-h forecasts).

Overall estimates of these attributes for the 6-h forecasts, as a function of lead time, are presented in Table 8. These results appear to be somewhat unusual, in the sense that skill is not a monotonically decreasing function of lead time. However, it should be noted that the four consecutive 6 -h periods constitute a 24 -h period and that precipitation events generally exhibit some diurnal variability in most locations. The observed relative frequencies of the two events of interest here increase as lead time increases-a result which is not very surprising when it is recognized that the 13-19, 19-25, 25-31, and 31-37 hour lead times correspond to the periods $2000-0200,0200-0800,0800-1400$, and 1400-2000, respectively. In this case, then, the usual effects of lead time on forecast quality are confounded with the effects of event relative frequency. In this regard, it is interesting to note that the RES values remain relatively constant or increase as lead time-and observed relative frequency-increases. The large value of REL associated with the 25-31 hour lead time for the $0.1 \mathrm{~mm}$ threshold is due primarily to substantial underforecasting for some lower probability values. Overall, the skill scores are positive for all four lead times for both thresholds for these $6-\mathrm{h}$ forecasts.

\section{d. Temperaturprognos till Vattenfall program}

This operational program involves the formulation of point and credible interval temperature forecasts. These forecasts are made once a day at 1900 for 0100 , 0700,1300 , and 1900 the following day for four locations in Sweden (see Fig. 1). The results presented here are based on forecasts produced during the eightmonth period from 16 September 1983 to 15 May 1984. Hourly temperature observations at the respective stations were used to verify the forecasts.

Since the fixed-width credible interval temperature forecasts are centered (in width) on the point estimates, it is of some interest to investigate first the quality of these point (i.e., unqualified) forecasts. In this regard, the average forecast, average observation, and selected overall measures of quality of the point forecasts for each station are presented in Table 9 . These results reveal a tendency toward a cold bias in the forecasts (average forecast temperature less than average observed temperature) at Stockholm and Göteborg. At Sundsvall and Malmö, any tendency toward a cold or warm bias is much less pronounced. When such tendencies are examined as a function of time of day (results omitted to conserve space), it is found that the cold bias is strongest at 0700 and that the warm bias (in a relative sense) is generally strongest at 1300 .

The accuracy of these point forecasts, as measured by the mean absolute error, ranges from $2.7^{\circ} \mathrm{C}$ at Sundsvall in northern Sweden to $1.5^{\circ} \mathrm{C}$ at Malmö in 

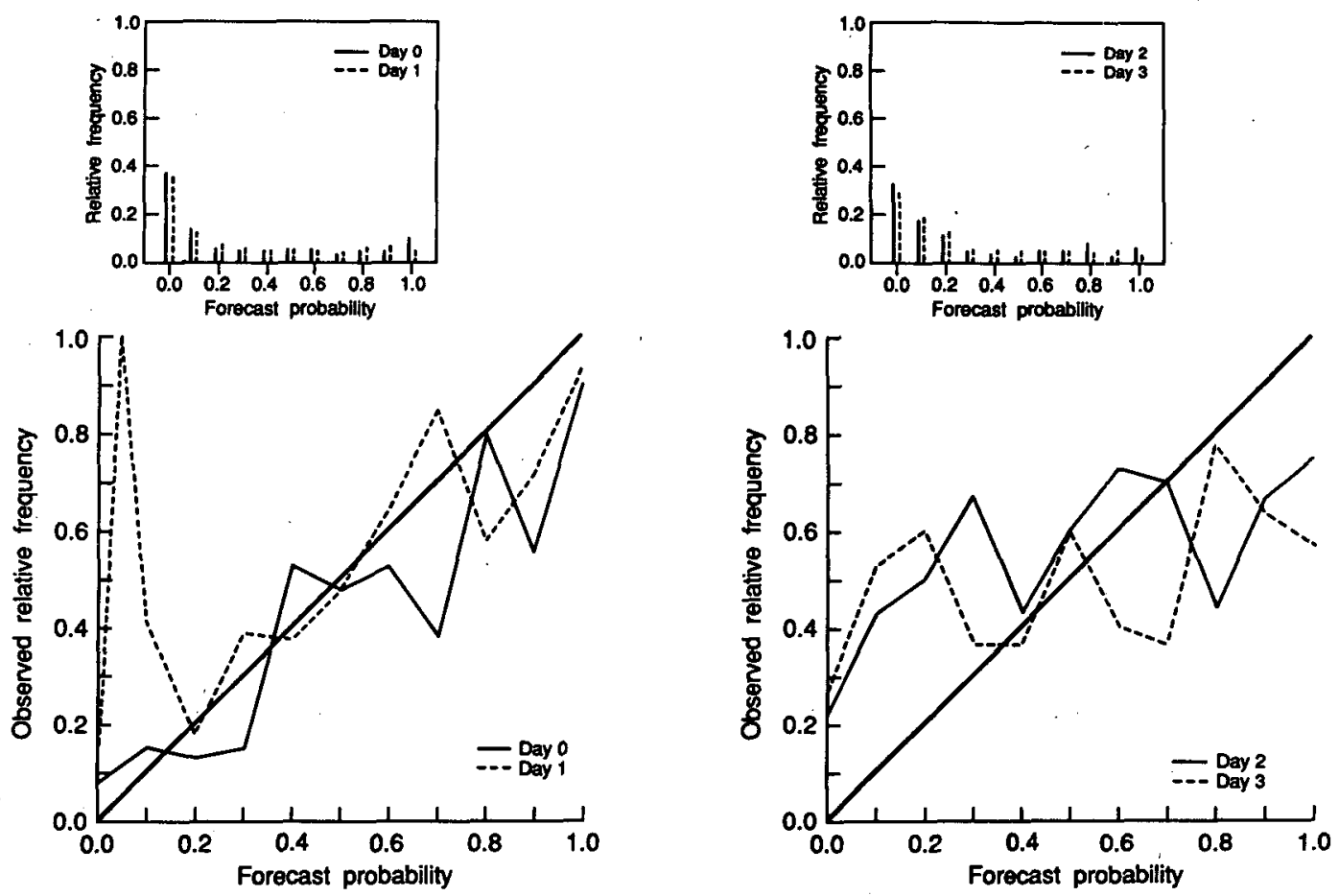

FIG. 5. Reliability diagrams for wind speed forecasts for $8 \mathrm{~m} \mathrm{~s}^{-1}$ threshold formulated in Byggväderprognoser program for (a) Days 0 and 1 and (b) Days 2 and 3. Insets contain frequency-of-use distributions for various probability values.

southern Sweden. The differences in accuracy among stations are undoubtedly due largely to differences in day-to-day variability of temperatures (larger in the north than in the south). When the results are stratified by time of day, it is found that accuracy is highest at 0100 or 1300 at all stations and that accuracy is lowest at 0700 at all stations except Malmö. The values of the correlation coefficient are indicative of the relatively high degree of correspondence between forecast and observed temperatures at all four locations.

If the point forecasts are considered to be estimates of the medians of the forecasters' subjective probability distributions, then the relative frequency of observed temperatures $(T)$ above the forecast temperatures $(F)$ should equal the relative frequency of observed temperatures below the forecast temperatures. The results in Table 9 reveal that $F<T$ almost twice as often as
$F>T$ for Stockholm and Göteborg, whereas the differences between $F<T$ and $F>T$ are much smaller for Sundsvall and Malmö. Not surprisingly, these results are consistent with the results related to the overall bias in the forecasts (discussed previously). Of course, since the point forecasts frequently may have represented the mean or some other statistic of the forecasters' distributions, any conclusions drawn from comparing these percentages must be treated cautiously.

The overall reliability of the fixed-width credible interval temperature forecasts can be assessed by comparing the average forecast probabilities and observed relative frequencies below the interval, in the interval, and above the interval. The relevant data are summarized in Table 10. These results indicate that, on the average, the probabilities assigned to the interval

TABLE 4. Overall reliability, resolution, and skill of wind speed forecasts formulated in Byggväderprognoser program for Norrköping for various lead times.

\begin{tabular}{ccccccrrr}
\hline \hline $\begin{array}{c}\text { Lead } \\
\text { time } \\
\text { (days) }\end{array}$ & $\begin{array}{c}\text { Average } \\
\text { valid } \\
\text { period } \\
\text { (hours) }\end{array}$ & $\begin{array}{c}\text { Number } \\
\text { of } \\
\text { forecasts }\end{array}$ & $\begin{array}{c}\text { Average } \\
\text { forecast } \\
\text { probability }\end{array}$ & $\begin{array}{c}\text { Observed } \\
\text { relative } \\
\text { frequency }\end{array}$ & $\begin{array}{c}\text { Brier score } \\
\text { for sample } \\
\text { climatology } \\
\text { BSSC }\end{array}$ & $\begin{array}{c}\text { Reliability } \\
\text { REL }\end{array}$ & $\begin{array}{c}\text { Resolution } \\
\text { RES }\end{array}$ & $\begin{array}{c}\text { Skill } \\
\text { score } \\
\text { SS (\%) }\end{array}$ \\
\hline 0 & 2 & 396 & 0.33 & 0.316 & 0.216 & 0.015 & 0.082 & 31.1 \\
1 & 8 & 297 & 0.32 & 0.397 & 0.240 & 0.035 & 0.060 \\
2 & 12 & 197 & 0.30 & 0.442 & 0.247 & 0.068 & 0.035 & -13.6 \\
3 & 12 & 198 & 0.30 & 0.449 & 0.247 & 0.093 & 0.024 \\
\hline
\end{tabular}



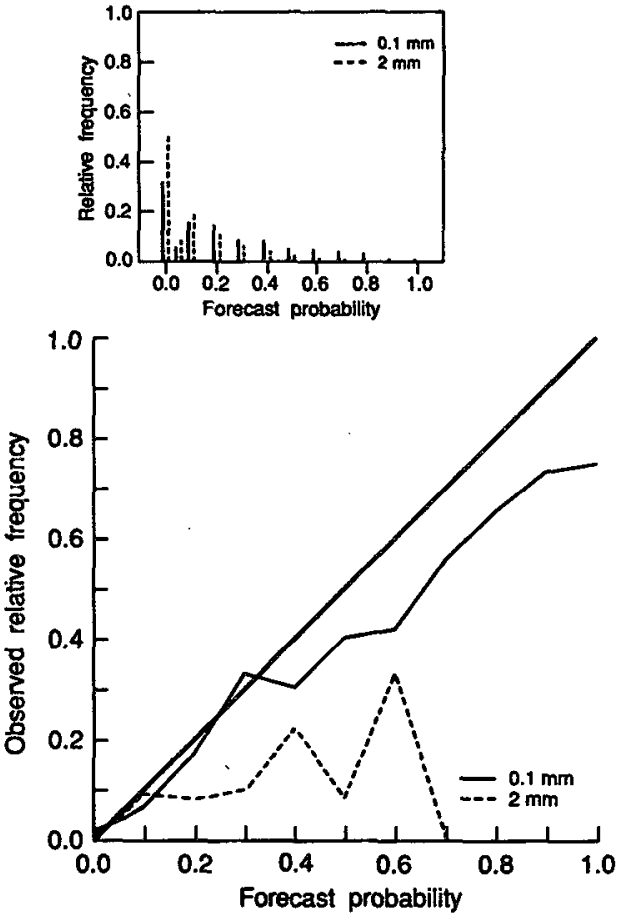

FIG. 6. Reliability diagrams for precipitation probability forecasts formulated in PROFARM program for 3-hour periods for $0.1 \mathrm{~mm}$ and $2 \mathrm{~mm}$ thresholds. Inset contains frequency-of-use distributions for various probability values.

are somewhat too high at Sundsvall, slightly too high at Stockholm and Göteborg, and "just right" at Malmö. Overall, the probabilities assigned to temperatures above and below the interval are of similar magnitudes, with only a slight tendency for the latter to exceed the former. On the other hand, examination of the observed relative frequencies above and below the interval reveals that the intervals at Stockholm and Göteborg are generally "placed" too low on the temperature scale (i.e., relative frequencies of observed temperatures above the interval exceed relative frequencies of observed temperatures below the interval). These results are consistent with the previously discussed cold biases in the point forecasts at these two locations (see Table 9).

With regard to the reliability of individual probability values for the three intervals, the relevant results are depicted in reliability diagrams in Fig. 8. For the fixedwidth interval itself (Fig. 8a), the empirical curves indicate that the reliability of the forecasts for Stockholm, Göteborg, and Malmö is quite good, although the slopes of the curves are smaller than the slope of the diagonal $45^{\circ}$ line. (Note: The "anomalous" points corresponding to a probability value of 0.50 are associated with very small subsamples of forecasts. See frequencyof-use diagrams.) At Sundsvall, the probabilities are consistently too high, at least for probability values exceeding 0.60 . For the interval below the fixed-width interval (Fig. 8b), underforecasting occurs for lower probability values and overforecasting occurs for higher probability values at all four stations. With regard to the interval above the fixed-width interval (Fig. 8c), underforecasting occurs across the entire range of probability values actually used at Sundsvall and Göteborg, whereas the reliability curve for Malmö possesses a slope considerably smaller than that of the $45^{\circ}$ line. It should be noted that, since the probabilities assigned to the three intervals must sum to one, the reliability curves for these intervals are not independent.

\section{e. Mäster Grön program}

This program involves the formulation of probabilistic forecasts of cloud amount for western Skåne, a small region in southern Sweden (see Fig. 1). Forecasts are prepared once a week and are valid for 12-h or 24$\mathrm{h}$ daytime periods on Days $1,2,3,4 / 5$, and 6/7. The probabilities specify the likelihood that the observed cloud amount (in eighths) will fall in each of three mutually exclusive and collectively exhaustive categories: 1) A: $0-2 / 8$; 2) B: $3 / 8-6 \% 8$; and 3) C: $7 / 8-1$. Averages of three hourly observations of cloud amount, in eighths, at a station in this region were used to verify these forecasts. The averages involved five observations in the case of the $12-\mathrm{h}$ periods and nine observations in the case of the $24-\mathrm{h}$ periods.

Empirical curves describing the reliability of the probabilities associated with the three cloud amount categories are depicted in Fig. 9. These curves are based on all forecasts formulated for Days 1,2 , and 3 during the periods April-September 1982 and March-September 1983 . For category A $\left(0 \sim^{2} / 8\right)$, substantial overforecasting occurs for probability values greater than 0.20 . In the case of the category $B(3 / 8-6 / 8)$ probabilities, the forecasts are quite reliable for higher probability

TABLE 5. Overall reliability, resolution, and skill of precipitation probability forecasts for three-hour periods formulated in PROFARM program from 16 April to 7 October 1985.

\begin{tabular}{ccccccrr}
\hline $\begin{array}{c}\text { Precipitation } \\
\text { amount } \\
\text { threshold } \\
(\mathrm{mm})\end{array}$ & $\begin{array}{c}\text { Number } \\
\text { of } \\
\text { forecasts }\end{array}$ & $\begin{array}{c}\text { Average } \\
\text { forecast } \\
\text { probability }\end{array}$ & $\begin{array}{c}\text { Observed } \\
\text { relative } \\
\text { frequency }\end{array}$ & $\begin{array}{c}\text { Brier score } \\
\text { for sample } \\
\text { climatology } \\
\text { BSSC }\end{array}$ & $\begin{array}{c}\text { Reliability } \\
\text { REL }\end{array}$ & $\begin{array}{c}\text { Resolution } \\
\text { RES }\end{array}$ & $\begin{array}{r}\text { Skill } \\
\text { score } \\
\text { SS (\%) }\end{array}$ \\
\hline 0.1 & 1112 & 0.22 & 0.188 & 0.153 & 0.005 & 0.038 & 21.3 \\
2 & 1112 & 0.10 & 0.053 & 0.050 & 0.010 & 0.004 & -13.3 \\
\hline
\end{tabular}


TABLE 6. Overall reliability, resolution, and skill of precipitation probability forecasts for three-hour periods formulated in PROFARM program for each lead time for (a) $0.1 \mathrm{~mm}$ threshold and (b) $2 \mathrm{~mm}$ threshold.

\begin{tabular}{|c|c|c|c|c|c|c|c|}
\hline $\begin{array}{l}\text { Lead } \\
\text { time } \\
\text { (hours) }\end{array}$ & $\begin{array}{l}\text { Number } \\
\text { of } \\
\text { forecasts }\end{array}$ & $\begin{array}{c}\text { Average } \\
\text { forecast } \\
\text { probability }\end{array}$ & $\begin{array}{c}\text { Observed } \\
\text { relative } \\
\text { frequency }\end{array}$ & $\begin{array}{c}\text { Brier score } \\
\text { for sample } \\
\text { climatology } \\
\text { BSSC }\end{array}$ & $\begin{array}{c}\text { Reliability } \\
\text { REL }\end{array}$ & $\begin{array}{c}\text { Resolution } \\
\text { RES }\end{array}$ & $\begin{array}{l}\text { Skill } \\
\text { score } \\
\text { SS (\%) }\end{array}$ \\
\hline \multicolumn{8}{|c|}{ (a) $0.1 \mathrm{~mm}$ threshold } \\
\hline $1-4$ & 278 & 0.20 & 0.184 & 0.150 & 0.009 & 0.076 & 44.7 \\
\hline $4-7$ & 278 & 0.22 & 0.180 & 0.148 & 0.010 & 0.039 & 19.3 \\
\hline $7-10$ & 278 & 0.25 & 0.205 & 0.163 & 0.015 & 0.035 & 12.1 \\
\hline $10-13$ & 278 & 0.23 & 0.184 & 0.150 & 0.010 & 0.024 & 9.7 \\
\hline \multicolumn{8}{|c|}{ (b) $2 \mathrm{~mm}$ threshold } \\
\hline $1-4$ & 278 & 0.09 & 0.036 & 0.035 & 0.015 & 0.005 & -28.4 \\
\hline $4-7$ & 278 & 0.09 & 0.065 & 0.061 & 0.008 & 0.007 & -1.4 \\
\hline $7-10$ & 278 & 0.11 & 0.058 & 0.054 & 0.013 & 0.004 & -15.1 \\
\hline $10-13$ & 278 & 0.10 & 0.054 & 0.051 & 0.016 & 0.008 & -16.3 \\
\hline
\end{tabular}

values but exhibit considerable underforecasting for probability values less than 0.50 . Finally, the category C $(7 / 8-1)$ forecasts reveal underforecasting for most lower probability values and substantial overforecasting for higher probability values. It should be noted that the fact that the probabilities must sum to one implies that when one category exhibits overforecasting (underforecasting), one or more other categories necessarily exhibit underforecasting (overforecasting).

The reliability, resolution, and skill of these probabilistic cloud amount forecasts are indicated in Table 11. Comparison of the average forecast probabilities and observed relative frequencies reveals that, overall, the category A forecasts exhibit overforecasting and the category $B$ forecasts exhibit underforecasting. The skill scores for all three categories are negative, indicating that forecasts based solely on the sample climatological probabilities are more accurate than the forecasts formulated by the forecasters. This absence of positive skill is, of course, directly related to the fact that the forecasts are relatively unreliable for substantial ranges of probability values. In this regard, the modest but not insignificant values of RES are more than offset by the relatively large values of REL (see Table 11).

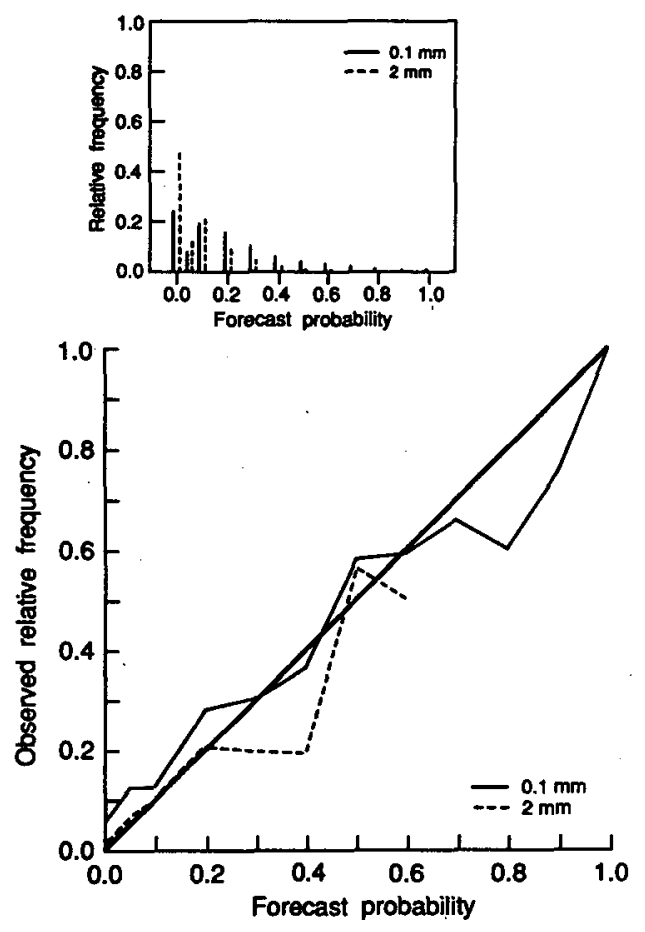

FIG. 7. As in Fig. 6 but for 6-hour periods.

\section{Discussion and conclusion}

In this section we first discuss the major features of the results presented in section 3 and compare these results with the results of other experimental and operational probability forecasting programs. When evaluating the results of the SMHI forecasting programs, it is important to understand the "conditions" under which the various probabilistic forecasts were formulated. In this regard, SMHI forecasters had no experience in probability forecasting prior to the initiation of the first specialized programs in 1980 and 1981. Moreover, subsequent programs have frequently involved the formulation of probabilistic forecasts for "new" elements or events for which experience was quite limited or even nonexistent. As yet, no operational system exists for providing the forecasters with formal and regular feedback regarding their individual and/or collective performance within any of the specialized forecasting programs. Moreover, until very recently, forecasters have not had available any objective guidance forecasts or other tailored products designed to provide them with "decision aids" in formulating their subjective probabilistic forecasts. Indeed, for some elements and events, the forecasters have possessed only very rough estimates of the relevant climatological 
TABLE 7. Overall reliability, resolution, and skill of precipitation probability forecasts for six-hour periods formulated in PROFARM program from 16 April to 7 October 1985.

\begin{tabular}{cccccccr}
\hline \hline $\begin{array}{c}\text { Precipitation } \\
\text { amount } \\
\text { threshold } \\
\text { (mm) }\end{array}$ & $\begin{array}{c}\text { Number } \\
\text { of } \\
\text { forecasts }\end{array}$ & $\begin{array}{c}\text { Average } \\
\text { forecast } \\
\text { probability }\end{array}$ & $\begin{array}{c}\text { Observed } \\
\text { relative } \\
\text { frequency }\end{array}$ & $\begin{array}{c}\text { Brier score } \\
\text { for sample } \\
\text { climatology } \\
\text { BSSC }\end{array}$ & $\begin{array}{c}\text { Reliability } \\
\text { REL }\end{array}$ & $\begin{array}{c}\text { Resolution } \\
\text { RES }\end{array}$ & $\begin{array}{r}\text { Skill } \\
\text { score } \\
\text { SS (\%) }\end{array}$ \\
\hline 0.1 & 1116 & 0.20 & 0.237 & 0.181 & 0.004 & 0.034 & 16.7 \\
2 & 1116 & 0.08 & 0.078 & 0.072 & 0.002 & 0.009 & 9.9 \\
\hline
\end{tabular}

probabilities of these events when the respective forecasting programs were initiated. In addition, some events for which these experimental and operational forecasts have been prepared are relatively rare, and the difficulties of making reliable and skillful forecasts for such events are widely recognized. Finally, the definitions of the events (categories, thresholds, intervals, etc.) for which the forecasts are formulated (see Table 1) indicate that many of these events are defined on relatively small space and time scales, and the problems associated with making skillful forecasts-whether probabilistic or nonprobabilistic-in such situations hardly requires discussion here.

Overall, we view the results of the probability forecasting components of SMHI's user-oriented forecasting programs as encouraging, in the sense that the forecasters are able to formulate fairly reliable and at least modestly skillful forecasts in many situations. On the other hand, it is clear from the results presented in section 3 that some forecasts exhibit substantial biases and that these biases can lead to marginally positive or even negative skill scores. In the course of this discussion, we will identify several factors that may contribute to such biases. Moreover, since similar biases have been found in other experimental and operational probability forecasting programs, it is of some interest to compare the results reported here with the results of these other programs. However, such comparisons are complicated by the fact that the conditions under which the forecasts were formulated (event definition, lead time, time of day, climatological probability, etc.) frequently vary markedly from program to program. This discussion begins with an examination of the results related to precipitation probability forecasts.

The Byggväderprognoser and PROFARM programs both involve precipitation probability forecasts for the $0.1 \mathrm{~mm}$ threshold. These forecasts generally exhibit some underforecasting for low probability values and overforecasting for high probability values, but they still possess appreciable skill for lead times out to approximately 36 hours. Skill is at best only marginally positive for forecasts of this event in the Byggväderprognoser program for longer lead times, due primarily to a lack of reliability in forecasts involving low probability values. In the PROFARM program, precipitation probability forecasts were also formulated for a 2 $\mathrm{mm}$ threshold. The results in this case are somewhat surprising in that the forecasts for 3-h periods on Day 0 are less reliable-and less skillful-than the forecasts for 6-h periods on Day 1. In fact, the former exhibit negative skill whereas the latter exhibit positive skill.

The precipitation probability forecasts formulated in these programs bear some resemblance to the probability of precipitation forecasts prepared in conjunction with operational forecasting programs in several other countries, including the United States and The Netherlands. In this regard, results from such operational programs appear to be somewhat better than the

TABLE 8. Overall reliability, resolution, and skill of precipitation probability forecasts for six-hour periods formulated in PROFARM program for each lead time for (a) $0.1 \mathrm{~mm}$ threshold and (b) $2 \mathrm{~mm}$ threshold.

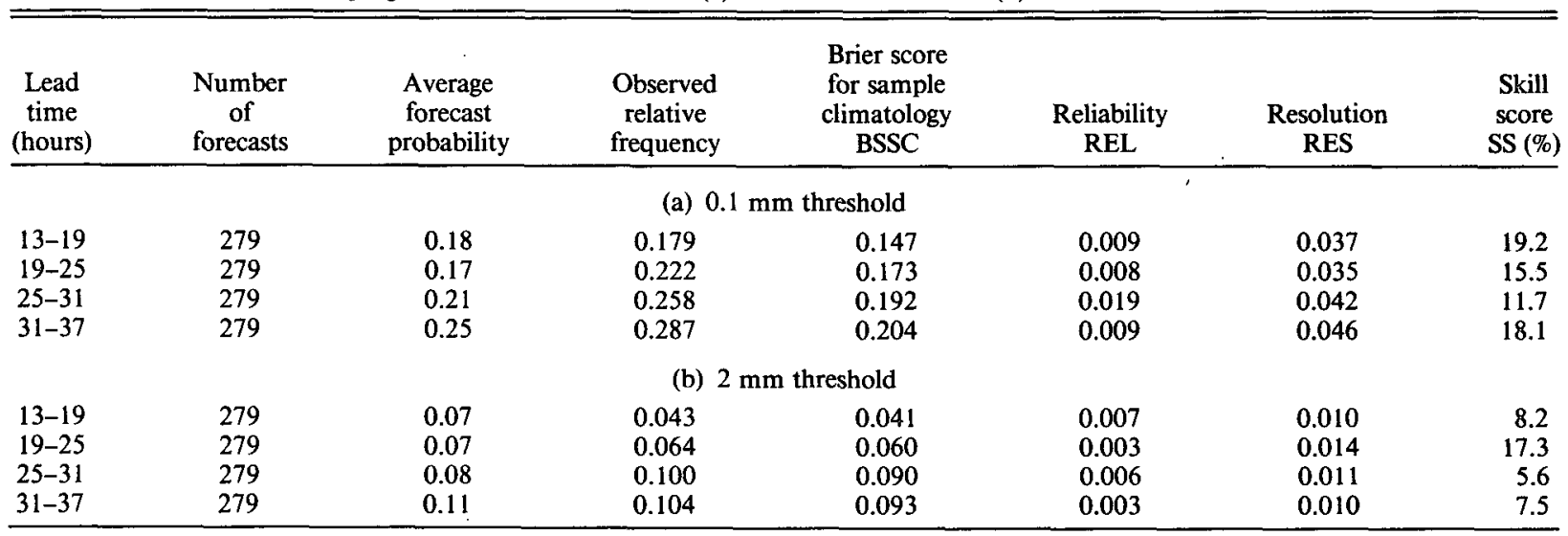


TABLE 9. Average forecast, average observation, and selected overall measures of quality of point tempirature forecasts formulated in Temperaturprognos till Vattenfall-program in 1983-84. $F$-forecast temperature, $T$-observed temperature, $r$-correlation coefficient (overbar denotes average). All temperatures in ${ }^{\circ} \mathrm{C}$.

\begin{tabular}{|c|c|c|c|c|c|c|c|c|c|}
\hline & A & & & & & & $F<T$ & $F=T$ & $F>T$ \\
\hline Station & forecasts & $\bar{F}$ & $\bar{T}$ & $\bar{F}-\bar{T}$ & $\overline{|F-T|}$ & $r$ & $(\%)$ & $(\%)$ & (\%) \\
\hline Sundsvall & 972 & -2.0 & -1.9 & -0.2 & 2.7 & 0.90 & 47.1 & 13.4 & 39.5 \\
\hline Stockholm & 972 & 1.8 & 2.4 & -0.6 & 1.7 & 0.93 & 51.1 & 21.5 & 27.5 \\
\hline Göteborg & 972 & 3.2 & 3.7 & -0.5 & 1.7 & 0.92 & 50.0 & 19.3 & 30.7 \\
\hline Malmö & 972 & 3.8 & 3.7 & 0.1 & 1.5 & 0.93 & 36.4 & 22.4 & 41.2 \\
\hline
\end{tabular}

results of these SMHI programs.(e.g., see Charba and Klein, 1980; Daan and Murphy, 1982; Murphy, 1985; Murphy and Brown, 1984; Murphy and Sabin, 1986). However, direct comparisons of such results may not be appropriate, because the SMHI programs involve different precipitation thresholds and/or shorter valid periods than the U.S. and Dutch programs. The quality of precipitation forecasts generally would be expected to decrease as the threshold value increases (e.g., Murphy et al., 1985) and as the length of the valid period decreases. On the other hand, the lead times associated with some SMHI precipitation probability forecasts are quite short, and quality usually increases as lead time decreases.

What factors may have adversely affected the reliability and skill of these SMHI precipitation probability forecasts? First, as noted earlier, the forecasters' lack of experience in probability forecasting and the absence of regular feedback to the forecasters regarding their performance undoubtedly tended to reduce the overall level of forecast quality. More specifically, some evidence exists to support the conclusion that the forecasters may not have "adjusted" their probabilities sufficiently when making forecasts for longer lead times or for shorter valid periods. In the Byggväderprognoser program, for example, the forecasters' used the probability value of zero less frequently when making forecasts for Days 2 and 3 than when making forecasts for Days 0 and 1 . However, the adjustment in this case evidently was not sufficient since the forecasts associated with zero probability for the longer lead times exhibit considerable underforecasting, which contributed to a marked decrease in skill. In addition, the Day 2 and Day 3 forecasts involved valid periods that av- erage at least twice the length of the valid periods for Days 0 and 1. (Note: The effects of lead time and length of valid period are confounded in this program, since they both increase from Day 0 to Day 2 or Day 3.) In the PROFARM program, precipitation probability forecasts were formulated for both 3-h and 6-h periods for the 0.1 and $2 \mathrm{~mm}$ thresholds. In the case of the 2 $\mathrm{mm}$ threshold forecasts, the skill of the 6-h forecasts exceeds the skill of the 3-h forecasts, despite the fact that the lead times associated with the former are all greater than the lead times associated with the latter. We believe that the forecasters may have failed to fully recognize the need to adjust their probabilities downward for the shorter valid periods; a conclusion which is supported by the tendency for forecast probabilities to exceed observed relative frequencies for most probability values. Alternatively, such overforecasting may be the result of a value-induced bias, which is frequently associated with forecasts of weather events that have a significant impact on users of the forecasts (e.g., see Murphy and Daan, 1984). This bias generally increases as the severity of the event increases (or, equivalently, as the climatological probability of the event decreases).

The Byggväderprognoser program also involves the formulation of probabilistic forecasts for snowfall amounts exceeding 0 and $3 \mathrm{~cm}$ thresholds. For the 0 $\mathrm{cm}$ snowfall forecasts, the results are similar to the 0.1 $\mathrm{mm}$ precipitation probability forecasts, in that overforecasting occurs for high probabilities at shorter lead times and underforecasting occurs for low probabilities at longer lead times. Since the D0 and D1 forecasts involve average valid periods less than or equal to 8 hours and the D2 and D3 forecasts involve 12-h valid periods, this result may be due to a failure to properly

TABLE 10. Average forecast probabilities and observed relative frequencies of credible interval temperature forecasts formulated in Temperaturpronos till Vattenfall program in 1983-1984. F-forecast temperature, $T$-observed temperature.

\begin{tabular}{|c|c|c|c|c|c|c|c|}
\hline \multirow[b]{2}{*}{ Station } & \multirow{2}{*}{$\begin{array}{l}\text { Number of } \\
\text { forecasts }\end{array}$} & \multicolumn{3}{|c|}{ Average forecast probabilities } & \multicolumn{3}{|c|}{ Obsierved relative frequencies } \\
\hline & & $T<F-3$ & $F-3 \leqslant T \leqslant F+3$ & $T>F+3$ & $T<F-3$ & $F-3 \leqslant T \leqslant F+3$ & $T>F+3$ \\
\hline Sundsvall & 972 & 0.10 & 0.82 & 0.08 & 0.14 & 0.71 & 0.15 \\
\hline Stockholm & 972 & 0.05 & 0.91 & 0.04 & 0.04 & 0.88 & 0.08 \\
\hline Göteborg & 972 & 0.05 & 0.91 & 0.04 & 0.04 & 0.88 & 0.07 \\
\hline Malmö & 972 & 0.04 & 0.93 & 0.04 & 0.04 & 0.93 & 0.03 \\
\hline
\end{tabular}



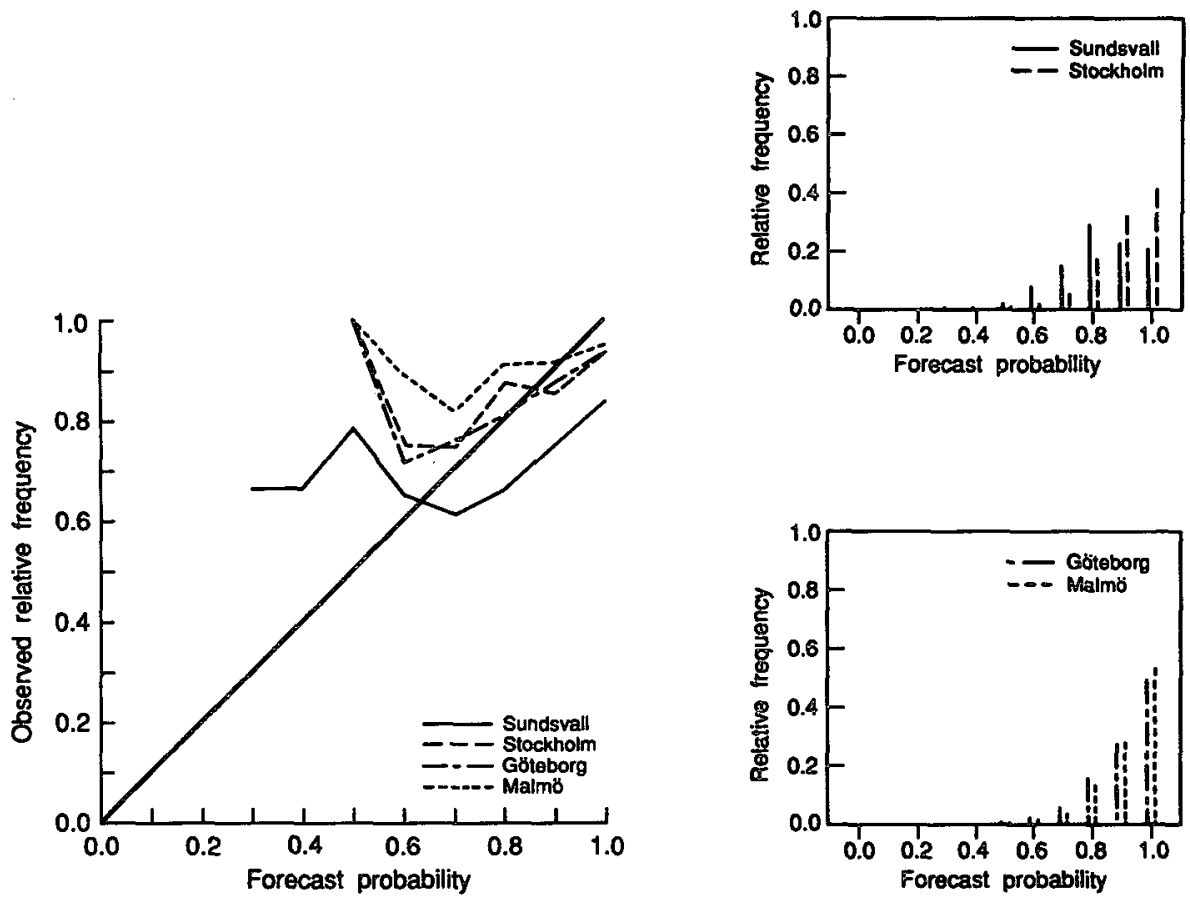

FIG. 8a. Reliability diagrams for probabilities assigned to fixed-width credible interval in Temperaturprognos till Vattenfall program.

adjust probabilities to account for the length of these periods. Nevertheless, the $0 \mathrm{~cm}$ threshold forecasts exhibit positive skill for all lead times. In the case of the
$3 \mathrm{~cm}$ snowfall forecasts, overforecasting occurs for most probability values and the skill of these forecasts is minimal. Similar overforecasting has been noted in
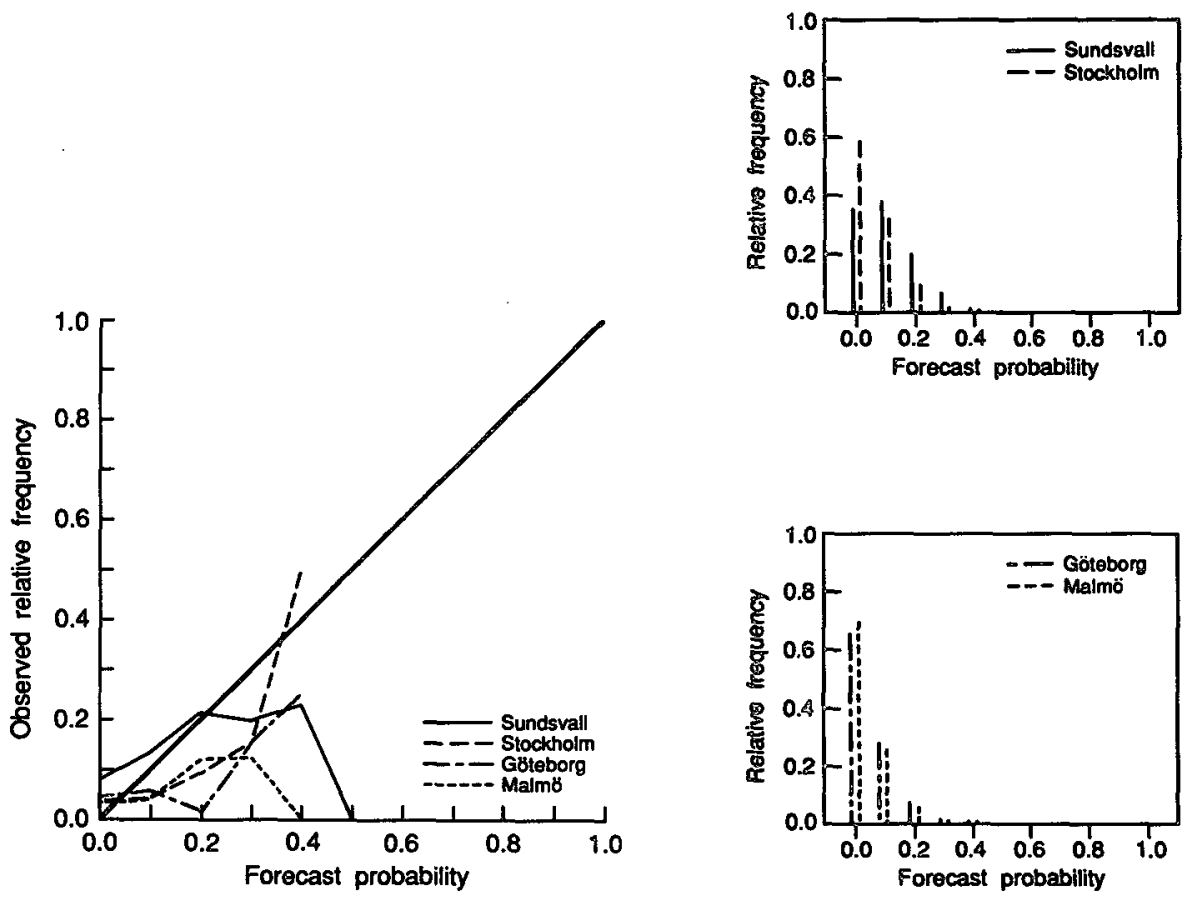

FiG. 8b. As in Fig. 8a but assigned to interval below fixed-width credible interval.

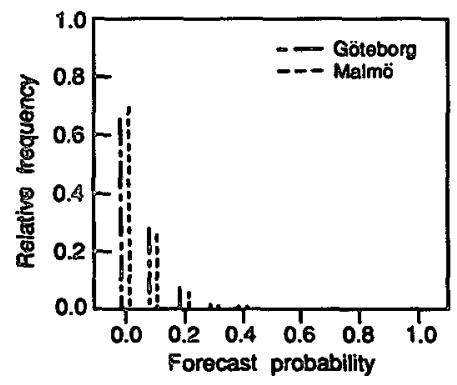



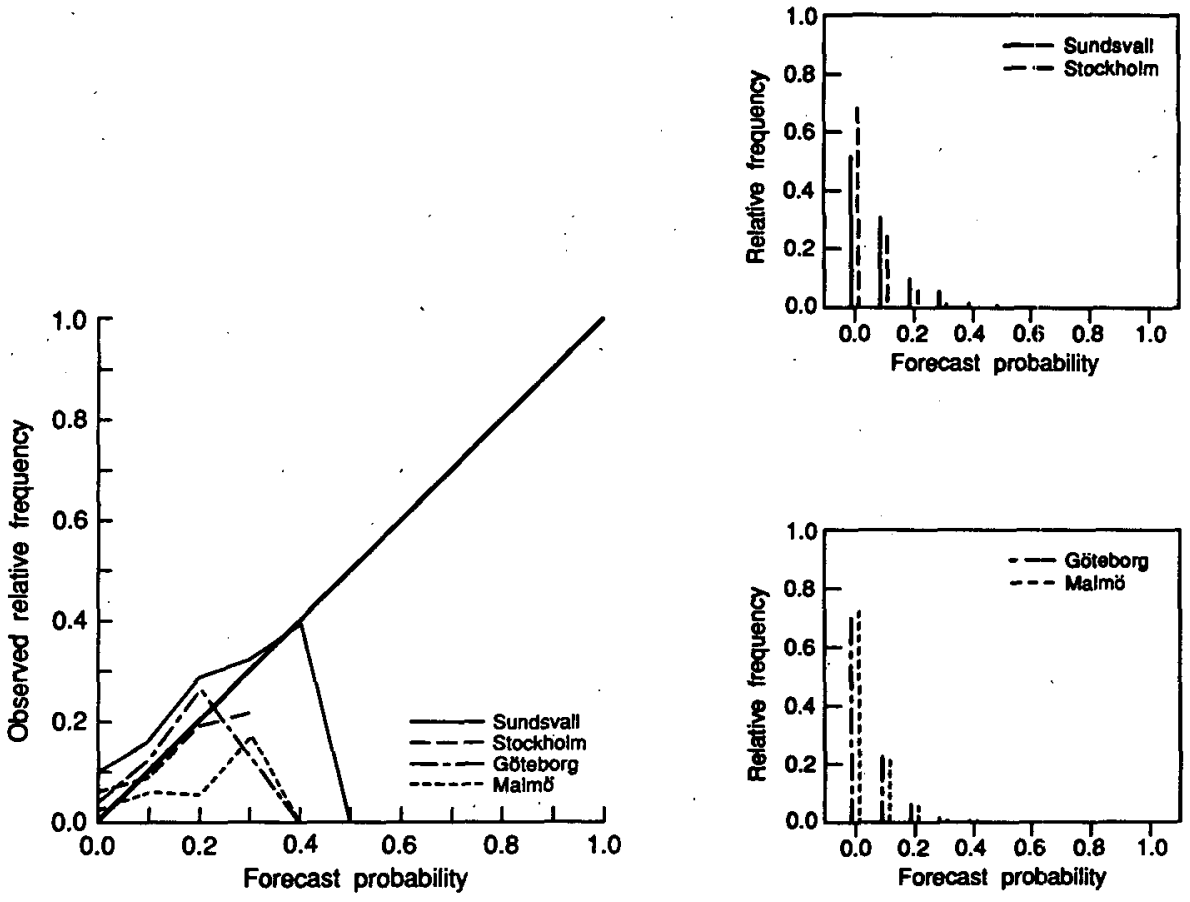

FIG. 8c. As in Fig. 8a but assigned to interval above fixed-width credible interval.

other programs involving probabilistic forecasts of relatively rare events (e.g., Murphy and Daan, 1984; Murphy et al., 1985; Murphy and Winkler, 1982).

Wind speed forecasts formulated in the Byggväderprognoser program exhibit underforecasting for low probability values and overforecasting for high probability values, and this tendency increases as lead time increases. As a result, skill scores that are strongly positive at shorter lead times become strongly negative at longer lead times. In this case, it is interesting to note that the frequency of use of the various probability values changes very little as lead time increases. These results suggest that the forecasters may not have fully recognized the need to reduce the frequency of use of relatively high and low probability values at longer lead times, in order to reflect the fact that their uncertainty generally increases as lead time increases. In addition, comparison of the average forecast probabilities and observed relative frequencies indicates that the forecasters may not have adequately adjusted their forecast probabilities for the length of the valid period (the latter increases as lead time increases).

The results of the Temperaturprognos till Vattenfall program are quite encouraging, in the sense that a relatively good correspondence exists between the average forecast probabilities and observed relative frequencies for the fixed-width credible intervals. However, a tendency was noted for the probabilities to be greater than the relative frequencies, which may be indicative of overconfidence on the part of the forecasters. Such overconfidence has also been found in other forecasting studies involving fixed-width credible intervals (e.g., Winkler and Murphy, 1979). In addition, it appears that some tendency exists for relative frequencies of observed temperatures above point and interval estimates to exceed relative frequencies of observed temperatures below these estimates. Since these temperature forecasts are used to estimate the demand for electric power and underestimating demand may be more serious than overestimating demand, this underforecasting may be the result of a "value-induced" bias (see Murphy and Daan, 1984).

Probabilistic cloud amount forecasts formulated in conjunction with the Mäster Grön program exhibit strong tendencies toward overforecasting for high probability values and cloud amount categories involving both small and large amounts and underforecasting for low probability values and cloud amount categories involving intermediate amounts. As a result, negative skill scores are obtained for all three cloud amount categories. We believe that this overforecasting and underforecasting may be due in part to day/night differences in the cloud amount distribution over these categories. The categories were originally defined to be approximately equally likely on a climatological basis over 24-h (daytime and nighttime) periods. However, Category B $(3 / 8-6 / 8)$ is more likely than the other two categories combined in the 12-h daytime periods for which these forecasts were actually formulated (see Table 11). Since some misperceptions may exist on the part of the forecasters regarding the overall likelihood of occurrence of the cloud amount categories, they 


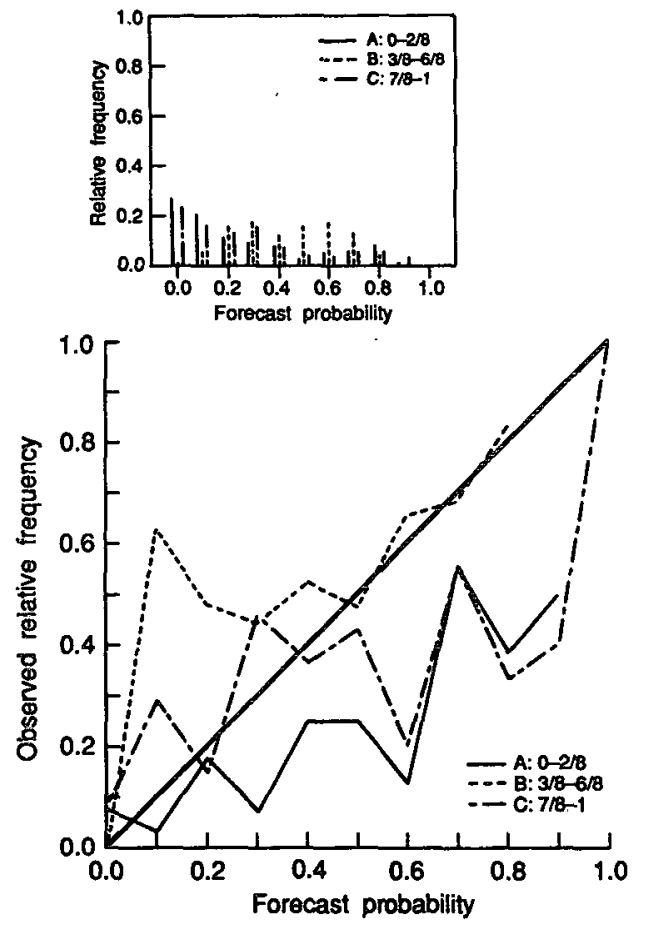

FIG. 9. Reliability diagrams for probabilistic forecasts formulated in Mäster Grön program for three categories of cloud amount. Inset contains frequency-of-use distributions for various probability values.

should be provided with such information as a starting point for the formulation of their forecasts.

This discussion and interpretation of the results has led to the identification of several factors that may have contributed to the biases-and associated lack of skillin the experimental and operational probability forecasts formulated by SMHI forecasters. These factors relate to various components of the forecasting process, and we believe that it should be possible to reduce such biases-and to increase the skill of the forecasts-by improving current procedures and practices associated with several components of this process. However, since the components of the forecasting process are interrelated, it is necessary to take a holistic approach in any serious effort to improve weather forecasts and enhance their usefulness. Such an approach has been adopted at SMHI, and the schematic diagram in Fig. 10 describes its overall forecasting system in terms of various developmental, operational, and evaluation components of the system and their interrelationships. Here, we briefly discuss several steps that are being taken to increase the efficiency and effectiveness of the forecasting system in Sweden.

For example, several efforts are underway that relate to the general problem of providing SMHI forecasters with new meteorological information that will complement the information currently available. As noted previously, even relevant climatological probabilities were not available when some new forecasting programs were initiated, and these probabilities are now being derived either by interpolating from historical data for existing stations or by analyzing data for the location of interest obtained during the experimental/ operational period. More generally, the PROMIS-90 program (Bodin, 1982), currently under development and implementation, is expected to provide SMHI forecasters with observations and analyses on much more detailed space and time scales in the near future. In addition, a concerted effort has been mounted to develop statistical and numerical-statistical procedures designed to provide the forecasters with objective guidance forecasts for the most important elements and events in the respective forecasting programs. These various sources of information should noticeably enhance the quality of the official forecasts formulated by SMHI forecasters.

Another set of efforts relates to the improvement of various facets of the subjective weather forecasting process. For example, despite the existence of many experimental and operational programs involving the formulation of probabilistic forecasts, most SMHI forecasters have had little formal training and quite limited experience in probability forecasting. As a result, a training program has been initiated to acquaint forecasters with basic concepts and methods in probability assessment and evaluation. This activity is part of a larger effort to modernize forecaster training in conjunction with the implementation of the PROMIS90 program.

The important and integral role of forecast evaluation in the forecasting system is highlighted in Fig. 10. In recognition of its importance, a comprehensive

TABLE 11. Overall reliability, resolution, and skill of precipitation probability forecasts of cloud amount in three categories formulated for Days 1,2 , and 3 combined in Mäster Grön program. Category A: $0-2 / 8$, Category B: $3 / 8-6 / 8$, Category C: $7 / 8-1$.

\begin{tabular}{cccccccc}
$\begin{array}{c}\text { Cloud } \\
\text { amount } \\
\text { category }\end{array}$ & $\begin{array}{c}\text { Number } \\
\text { of } \\
\text { forecasts }\end{array}$ & $\begin{array}{c}\text { Average } \\
\text { forecast } \\
\text { probability }\end{array}$ & $\begin{array}{c}\text { Observed } \\
\text { relative } \\
\text { frequency }\end{array}$ & $\begin{array}{c}\text { Brier score } \\
\text { for sample } \\
\text { climatology } \\
\text { BSSC }\end{array}$ & $\begin{array}{c}\text { Reliability } \\
\text { REL }\end{array}$ & $\begin{array}{c}\text { Resolution } \\
\text { RES }\end{array}$ & $\begin{array}{c}\text { Skill } \\
\text { score } \\
\text { SS (\%) }\end{array}$ \\
\hline A & 150 & 0.272 & 0.160 & 0.134 & 0.041 & 0.022 & -14.1 \\
B & 150 & 0.438 & 0.553 & 0.247 & 0.033 & 0.013 & -7.8 \\
C & 150 & 0.290 & 0.287 & 0.204 & 0.040 & 0.027 \\
\hline
\end{tabular}




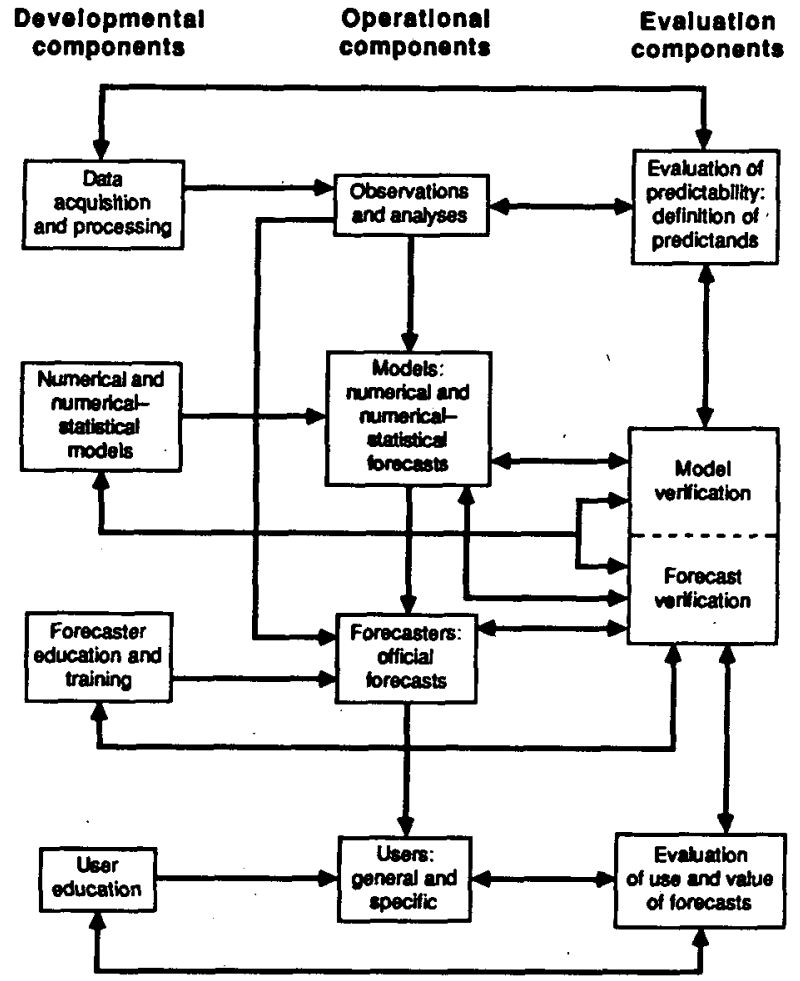

FIG. 10. Schematic diagram describing forecasting system at SMHI in terms of developmental, operational, and evaluation components and their interrelationships.

forecast verification system is currently under development at SMHI. This system has been designed to provide forecasters with individual and collective feedback on a timely basis. Such feedback has been shown to be quite effective in reducing the overforecasting that frequently occurs in the early stages of probability forecasting programs (e.g., Murphy and Daan, 1984).

Users of weather forecasts also represent an essential component of the forecasting system, as indicated in Fig. 10. Interactions between users and forecasters are essential to ensure that the forecasting system is responsive to user needs and that the users are fully aware of the system's capabilities and limitations. At SMHI, forecasters maintain regular contacts with users, both on a real-time basis and on an annual basis to review and evaluate the effectiveness of the respective forecasting programs. Since the overall efficiency of a forecasting system necessarily depends on the usefulness of the forecasts (as well as their quality), the importance of these interactions and contacts cannot be overemphasized.
Acknowledgments. George Ericsson, Bo Lindgren, and Peter Murphy made significant contributions to the data analysis phase of this study. The study was initiated during the period June-October 1984 when the fourth author (AHM) was a visiting scientist at the Swedish Meteorological and Hydrological Institute. His participation in the study also was supported in part by the National Science Foundation (Division of Atmospheric Sciences) under Grants ATM-8209713 and ATM-8507495.

\section{REFERENCES}

Bodin, S., 1982: Blueprint for the future Swedish weather service system. Nowcasting, K. A. Browning, Ed., Academic Press, 2536.

Brier, G. W., 1950: Verification of forecasts expressed in terms of probability. Mon. Wea. Rev., 78, 1-3.

Charba, J. P., and W. H. Klein, 1980: Skill in precipitation forecasting in the National Weather Service. Bull. Amer. Meteor. Soc., 61, $1546-1555$.

Daan, H., and A. H. Murphy, 1982: Subjective probability forecasting in The Netherlands: some operational and experimental results. Meteor. Rundsch., 35, 99-112.

Krzysztofowicz, R., 1983: Why should a forecaster and a decision maker use Bayes' theorem? Water Resour. Res., 19, 327-336.

Murphy, A. H., 1973: A new vector partition of the probability score. J. Appl. Meteor., 12, 595-600.

- 1977: The value of climatological, categorical and probabilistic forecasts in the cost-loss ratio situation. Mon. Wea. Rev., 105, 803-816.

_ 1985: Probabilistic weather forecasting. Probability, Statistics, and Decision Making in the Atmospheric Sciences. A. H. Murphy and R. W. Katz, Eds., Westview Press, 337-377.

- , and R. L. Winkler, 1974: Credible interval temperature forecasting: some experimental results. Mon. Wea. Rev., 102, 784794.

- , and,- 1977 : Reliability of subjective probability forecasts of precipitation and temperature. Appl. Stat., 26, 41-47.

- , and - 1982: Subjective probabilistic tornado forecasting: some experimental results. Mon. Wea. Rev., 110, 1288-1297.

- and B. G. Brown, 1984: A comparative evaluation of objective and subjective weather forecasts in the United States. $J$. Forecasting, 3, 369-393.

- , and H. Daan, 1984: Impacts of feedback and experience on the quality of subjective probability forecasts: comparison of results from the first and second years of the Zierikzee experiment. Mon. Wea. Rev., 112, 413-423.

and Decision Making in the Atmospheric Sciences, A. H. Murphy and R. W. Katz, Eds., Westview Press, 379-437.

- , and T. E. Sabin, 1986: Trends in the quality of National Weather Service forecasts. Wea. Forecasting, 1, 42-55.

, W.-R. Hsu, R. L. Winkler and D. S. Wilks, 1985: The use of probabilities in subjective quantitative precipitation forecasts: some experimental results. Mon. Wea. Rev., 113, 2075-2089.

Sanders, F., 1963: On subjective probability forecasting. J. Appl. Meteor., 2, 191-201.

Winkler, R. L., and A. H. Murphy, 1979: The use of probabilities in forecasts of maximum and minimum temperatures. Meteor. Mag., 108, 317-329. 